\title{
Divisia monetary aggregates for a heterogeneous euro area
}

\author{
Maximilian C. Brill ${ }^{1}$. Dieter Nautz ${ }^{2} \cdot$ Lea Sieckmann ${ }^{2}$ \\ Published online: 30 August 2020 \\ (c) The Author(s) 2020
}

\begin{abstract}
Since the run-up to the great recession, there has been a significant degree of heterogeneity across euro area countries both in terms of interest rates and in the composition of monetary assets. In order to account for the heterogeneity of monetary assets within and across member countries, we propose a Divisia monetary aggregate for the euro area. In line with earlier evidence obtained for the United States, our results from a panel probit analysis show that the divergence between the Divisia and the simple sum aggregate has a significant predictive content for recessions in euro area countries.
\end{abstract}

Keywords Monetary aggregation · Euro area Divisia aggregate $\cdot$ Recessions

JEL Classification E51 $\cdot$ E32 $\cdot$ C43

\section{Introduction}

The role of money for monetary policy analysis has changed remarkably in recent years. In the early years of the European Monetary Union, for example, the European Central Bank (ECB) placed a lot of emphasis on the role of monetary

\footnotetext{
We thank two referees for their very helpful comments. We are also grateful for suggestions received by seminar participants at the European Central Bank, at the annual meeting of the Society for Economic Measurement (SEM) in Frankfurt and the 6th International Conference on Time Series and Forecasting (ITISE) in Granada.

Dieter Nautz

dieter.nautz@fu-berlin.de

Maximilian C. Brill

maximilian.brill@uantwerpen.be

Lea Sieckmann

1.sieckmann@fu-berlin.de

1 Department of Economics, University of Antwerp, Prinsstraat 13, 2000 Antwerp, Belgium

2 Department of Economics, Freie Universität Berlin, Boltzmannstrasse 20, 14195 Berlin, Germany
} 
aggregates for its monetary policy analysis. The ECB even published a reference value for money growth in order to explain its interest rate decisions. Yet, this prominent role of money has never been beyond controversy. On the one hand, the empirical literature raised doubts on the stability of money demand and, thus, on the information content of monetary aggregates for inflation and output. On the other hand, the theoretical literature assumed that monetary policy is fully reflected in interest rates and money virtually disappeared from standard macro models. In accordance with the declining role of money for both, monetary theory and monetary policy practice, the ECB downplayed the role of monetary aggregates for its interest rate decisions, see e.g. European Central Bank (2003) or Constâncio (2018).

Since the outbreak of the financial crisis, there has been a renewed interest in the analysis of monetary aggregates. To illustrate, Billi et al. (2020) reconsider money growth targeting as a monetary policy tool in the current low-interest-rate environment. However, traditional simple sum aggregates may not accurately measure the quantities of monetary services and the availability of liquidity. Following Barnett (1980), monetary analysis should be based on Divisia aggregates where different monetary components, like currency and time-deposits, are weighted by their individual and time-varying expenditure shares. In contrast to their simple sum counterparts, Divisia aggregates account for the substitution effects between different types of monetary assets.

There is increasing empirical evidence that Divisia aggregates contain useful information for the real economy. Early evidence of superior forecasting ability of U.S. Divisia aggregates for output relative to simple sum aggregates is provided by Schunk (2001). Barnett and Chauvet (2011) observe that U.S. monetary aggregates and their Divisia counterparts diverge particularly during times of high uncertainty indicating that this divergence can be used as a signal for impending recessions. More recently, Belongia and Ireland (2015) and Dery and Serletis (2020) confirm the information content of Divisia aggregates for the United States.

A small but increasing number of central banks publish Divisia aggregates, including the Bank of England (Hancock 2005) and the Federal Reserve Bank of St. Louis (Anderson and Jones 2011). Divisia monetary aggregates for the United States are also provided by the Center of Financial Stability (CFS), see Barnett et al. (2013). Stracca (2004) made a first attempt to compute a Divisia monetary aggregate for the euro area. Assuming that euro area countries have already converged, he applied a single euro area wide interest rate for each of the monetary assets. Darvas (2015) proposed a Divisia aggregate for the euro area under similar homogeneity assumptions. However, since the run-up to the great recession, there has been a significant degree of heterogeneity in the level of interest rates and the composition of monetary assets in the euro area. El-Shagi and Kelly (2019) account for the heterogeneity of the euro area but restrict the attention to the analysis of country-specific liquidity measures. Using data until 2013, they find that country-specific Divisia aggregates contain useful information on macroeconomic dynamics.

In the current paper, we also compute country-specific Divisia aggregates in a first step. In a second step, however, we apply Barnett (2007)'s theory on monetary aggregation across countries and propose a euro area wide Divisia aggregate 
Table 1 Simple sum monetary aggregates

\begin{tabular}{lll}
\hline Monetary asset & M1 & M2 \\
\hline Currency in circulation & $\mathrm{x}$ & $\mathrm{x}$ \\
Overnight deposits & $\mathrm{x}$ & $\mathrm{x}$ \\
Deposits with agreed maturities of up to 2 years & & $\mathrm{x}$ \\
Deposits redeemable at notice of up to 3 month & & $\mathrm{x}$ \\
\hline
\end{tabular}

The Table presents the components of the monetary aggregates M1 and $\mathrm{M} 2$ in the euro area, following the definition by European Central Bank (2012)

that allows for both, country-specific interest rates and heterogeneous monetary developments. ${ }^{1}$

The analysis of the euro area wide Divisia aggregate confirms the importance of country-specific monetary developments. Particularly since the outbreak of the financial crisis, user cost and expenditure shares of monetary assets and, thereby, Divisia aggregates differ significantly across euro area countries. Building on Barnett and Chauvet (2011), we are particularly interested in the predictive content of the divergence between simple sum and Divisia aggregates for recession periods. Therefore, we perform a probit analysis that exploits the ongoing heterogeneity of business cycles in the euro area and the panel dimension of our data set. Our results confirm that the divergence between simple sum and Divisia aggregates predict recessions in individual euro area countries. In particular, predictions based on Divisia aggregates clearly outperform models that ignore monetary aggregates and only include information from short- and long-term interest rates.

The rest of the paper is structured as follows. Section 2 recalls how to compute Divisia aggregates in a heterogeneous currency union. Section 3 presents and discusses the data. Section 4 analyzes the Divisia aggregates and its components at a country level. The focus of Sect. 5 is on the resulting euro area wide aggregate. Section 6 investigates the predictive content of monetary aggregates for recessions and Sect. 7 concludes.

\section{Monetary aggregation}

\subsection{Simple sum aggregates}

Defining and measuring the amount of money in the economy is not straightforward. On the one hand, monetary aggregates differ because they include different types of assets. While narrow aggregates may include only currency in circulation and overnight deposits, broader measures additionally consider longer-term savings deposits, compare Table 1.

\footnotetext{
${ }^{1}$ In doing so, our work is also related toBarnett and Gaekwad (2018) with, however, some important differences regarding country selection and data adjustment, see Sect. 3 for more details.
} 
On the other hand, it is not obvious how different asset types should be aggregated. For example, the widely-used monetary aggregates M1 and M2 simply add up the asset quantities implying that different monetary assets are treated as perfect substitutes. Simple sum aggregates do not take into account the different degrees of liquidity provided by its components. Therefore, simple sum monetary aggregates do not change even in the presence of large shifts in their composition and, thus, in the availability of monetary services. Consider, for example, a situation where time deposits are withdrawn on a large scale and completely converted into cash. In this extreme scenario, the liquidity conditions of the economy change dramatically but the simple sum monetary aggregate remains unaffected. Disregarding differences in opportunity costs and therefore the substitution effect between monetary assets may lead to a distorted picture of liquidity services available in the economy. Jadidzadeh and Serletis (2019) reject the appropriateness of the aggregation assumptions for all the money measures published by the Federal Reserve. According to (Belongia and Ireland 2014, p. 5), the only question about simple sum aggregates is the magnitude of their measurement error.

\subsection{Divisia monetary aggregates}

Barnett (1980) applies aggregation and statistical index number theory to derive the optimal aggregate measure of liquidity services. The Divisia aggregate incorporates the concept of user costs developed by Barnett (1978), which can be interpreted as the opportunity costs of a monetary asset, i.e. how much a consumer is willing to give up in order to hold a certain asset, with more liquid assets having higher user cost. Specifically, the Divisia aggregate $D_{t}$ is defined in terms of its growth rate by:

$$
\ln D_{t}-\ln D_{t-1}=\sum_{i} v_{i t}\left(\ln M_{i t}-\ln M_{i t-1}\right),
$$

where the growth rate $\ln M_{i t}-\ln M_{i t-1}$ of monetary asset $i$, is weighted by $v_{i t}=\frac{s_{i t-1}+s_{i t}}{2}$, the two-period average of its expenditure share $s_{i t}$ :

$$
s_{i t}=\frac{p_{i t} M_{i t}}{\sum p_{i t} M_{i t}} .
$$

Finally, $p_{i t}$ denotes the user cost of asset $i$ in period $t$ in discrete time:

$$
p_{i t}=\frac{R_{t}-r_{i t}}{R_{t}+1}
$$

where $r_{i t}$ denotes the rate of return on asset $i$ in period $t$ and $R_{t}$ is the benchmark rate. The benchmark rate is the expected yield on a pure investment, i.e. an asset that provides no services other than its yield. The user cost can therefore be interpreted as the interest which is given up in order to hold a liquid monetary asset.

There are two cases where a Divisia and its corresponding simple sum aggregate provide the same information and will move in parallel. First, Divisia and simple sum aggregates can only differ if the underlying monetary assets are actually heterogeneous, 
i.e. if different assets have different opportunity cost $\left(p_{i t}\right)$. In recent years, however, deposit rates $\left(r_{i t}\right)$ have converged to zero in many euro area countries for most of the monetary assets. As a result, opportunity cost of different assets coincide [Eq. (3)] and the growth rates of Divisia and simple sum aggregates can be expected to be similar. Second, irrespective of the user cost, Divisia and simple sum aggregates grow with the same rate if the various monetary assets $\left(M_{i t}\right)$ grow with identical rates, see Eq. (1). By contrast, the difference between a Divisia index and its simple sum counterpart should be particularly pronounced in uncertain times when the composition of money holdings change significantly. Consequently, Barnett and Chauvet (2011) suggest that the divergence between the Divisia and its simple sum counterpart could be a useful indicator for recessions.

\subsection{Divisia monetary aggregates in a currency union}

The previous subsection discussed monetary aggregation within a single country. Let us now turn to monetary aggregation across countries in order to define a Divisia aggregate for a currency union. Barnett (2007) developed a theory for the aggregation across countries assuming different degrees of homogeneity. At the one end of the scale, he considers a perfectly homogenous currency union where money demand characteristics and user costs for each monetary asset coincide across countries. This assumption may be less critical for the pre-crisis period when both, short- and long-term interest rates were very similar across the euro area. However, in the run-up to the great recession and during the European debt crisis longer-term interest rates diverged significantly between crisis- and non-crisis countries. In such periods, benchmark rates and, thereby, user cost for the same type of monetary asset could be very different across euro area countries. At the other end of the scale, Barnett (2007) considers a multi-country area with distinct currencies and time-varying exchange rates. In the following, we apply this model to the case of a currency union. Thus, while the exchange rate is constant, the member countries of the currency union are still heterogeneous because the growth rates of certain monetary assets and the corresponding user cost are allowed to vary between countries.

Following Barnett (2007), the construction of the area wide aggregate proceeds in two steps. In a first step, Divisia quantity aggregates $D_{k}$ for each individual country $k$ are defined according to Eq. (1). In a second step, the country-specific Divisia quantity indices are aggregated to the area wide Divisia index $D M U$ as follows:

$$
\ln D M U_{t}-\ln D M U_{t-1}=\sum_{k} V_{k t}\left[\ln \left(h_{k t} D_{k t}\right)-\ln \left(h_{k t-1} D_{k t-1}\right)\right]
$$

In accordance with Eq. (1), the area wide Divisia aggregate $D M U$ is defined in terms of its growth rates which are the weighted sum of the country-specific Divisia growth rates. The country weights are the two-period averages $V_{k t}=\frac{S_{k t-1}+S_{k t}}{2}$ of the countries expenditure shares $S_{k t}$ 


$$
S_{k}=\frac{D_{k} \Pi_{k}^{*} h_{k}}{\sum D_{k} \Pi_{k}^{*} h_{k}}
$$

where we suppressed time-subscripts for notational convenience. The monetary user-cost price aggregate $\Pi_{k}^{*}$ measures the opportunity cost of holding a unit of $D_{k}$ in country $k$. According to Barnett (2007) it is defined for each country as:

$$
\ln \left(\Pi_{k t}^{*}\right)-\ln \left(\Pi_{k t-1}^{*}\right)=\sum_{i} v_{k i t}\left(\ln \left(p_{k i t}\right)-\ln \left(p_{k i t-1}\right)\right)
$$

The country's $k$ population share is denoted by $h_{k}$. In contrast to e.g. user cost, population shares (like other measures of economic size, including the GDP share) did not change significantly over the last 15 years in the euro area. Therefore, changes in the size of a member country play no important role for the evolution of the euro area Divisia aggregate.

\section{Data}

While Darvas (2015) provides a Divisia aggregate under the assumption of homogeneous interest rates across countries, there is still no publicly available Divisia aggregate that takes into account the heterogeneity of the euro area. In this section, we compute a euro area wide Divisia aggregate by adopting the heterogeneous country approach of Barnett (2007). The data for the Divisia computation is publicly available from the ECB Statistical Data Warehouse. ${ }^{2}$

\subsection{Countries under consideration}

In the following, we compute a Divisia monetary aggregate for the first 12 countries (EA-12) that adopted the Euro. For these countries all data series are available on a monthly basis from January 2003 onward. The data employed in the current paper end in August 2018. The 12 euro area countries under consideration account for more than $95 \%$ of the unions population and more than $97 \%$ of GDP, compare Table 2.

Barnett and Gaekwad (2018) calculate a Divisia aggregate for a different set of countries including Estonia, Finland, France, Germany, Ireland, Italy, Luxembourg, Malta, the Netherlands, Slovakia, and Slovenia. Note that this group of countries covers a significantly lower share of the euro area, both in terms of population and GDP. A further advantage of using EA-12 countries is that they have adopted the Euro already in 2003. Therefore, the EA-12 index does not require any assumptions about exchange rates.

\footnotetext{
${ }^{2}$ For a full list of the data see Table 5.
} 
Table 2 The relative size of euro area countries

\begin{tabular}{|c|c|c|c|}
\hline Country & Adoption of euro & $\begin{array}{l}\text { Population } \\
\text { share in \% } \\
(2018)\end{array}$ & $\begin{array}{l}\text { GDP share } \\
\text { in } \%(2017)\end{array}$ \\
\hline Austria & 1999-01-01 & 2.58 & 3.30 \\
\hline Belgium & 1999-01-01 & 3.34 & 3.92 \\
\hline Finland & 1999-01-01 & 1.61 & 2.00 \\
\hline France & 1999-01-01 & 19.69 & 20.45 \\
\hline Germany & 1999-01-01 & 24.26 & 29.25 \\
\hline Ireland & 1999-01-01 & 1.42 & 2.62 \\
\hline Italy & 1999-01-01 & 17.71 & 15.39 \\
\hline Luxembourg & 1999-01-01 & 0.18 & 0.49 \\
\hline The Netherlands & 1999-01-01 & 5.01 & 6.58 \\
\hline Portugal & 1999-01-01 & 3.01 & 1.74 \\
\hline Spain & 1999-01-01 & 13.66 & 10.41 \\
\hline Greece & 2001-01-01 & 3.14 & 1.61 \\
\hline EA-12 & & 95.61 & 97.76 \\
\hline Slovenia & 2007-01-01 & 0.61 & 0.38 \\
\hline Cyprus & 2008-01-01 & 0.25 & 0.17 \\
\hline Malta & 2008-01-01 & 0.14 & 0.10 \\
\hline Slovakia & 2009-01-01 & 1.59 & 0.76 \\
\hline Estonia & 2011-01-01 & 0.39 & 0.21 \\
\hline Latvia & 2014-01-01 & 0.57 & 0.24 \\
\hline Lithuania & 2015-01-01 & 0.82 & 0.38 \\
\hline EA-19 & & 100 & 100 \\
\hline
\end{tabular}

In the euro area, population shares and GDP shares did not change significantly over the past 20 years. The presented numbers refer to 2018 and 2017, respectively

\subsection{Monetary assets and transactions data}

In the rest of the paper, the focus is on computing M2 Divisia aggregates, i.e. the country-specific and EA-12 wide Divisia aggregate that correspond to the simple sum aggregate M2. ${ }^{3} \mathrm{M} 2$ consists of four types of assets: (1) currency in circulation, (2) overnight deposits, (3) deposits with agreed maturity of up to 2 years and (4) deposits redeemable at notice of up to 3 month. The computation of a Divisia index requires for each monetary asset country-specific data for its volume and the corresponding interest rate. For each of the four monetary assets, volumes are published as monetary financial institution (MFI) balance sheet statistics, for which a detailed description can be found in European Central Bank (2012).

Currency in circulation can only be proxied at the country level, since currency flows freely within the euro area. The allocation of currency to individual countries

\footnotetext{
${ }^{3}$ Since M1 considers only two types of assets, the difference between the M1 Divisia and M1 is only small.
} 
within a monetary union is still an open issue, see Dias (2018). Nautz and Rondorf (2011), for example, construct country-specific simple sum monetary aggregates excluding currency. However, given their importance for the liquidity situation of a country, currency holdings cannot be ignored in a Divisia aggregate. El-Shagi and Kelly (2019) use "currency put into circulation by each country's central bank on behalf of the ECB" as reported by the IMF. However, the IMF data is only available until 2013 and implies implausible negative currency holdings for some countries in some periods. Therefore, we follow the ECB and estimate the country-specific currency in circulation based on a country's share in the ECB's capital.

Deposits might exit or enter the market. In fact, the level of certain deposits drop to zero at some point in time in some countries. In order to avoid undefined growth rates, we follow Barnett et al. (2013) and calculate growth rates only if deposits are non-zero in two consecutive periods.

The level data provided by the ECB are not adjusted for breaks and shifts due to reclassification or reevaluation of assets. However, simple reclassifications of assets do not represent changes in liquidity and, therefore, should not affect the Divisia aggregate. In the euro area, the shifts in the levels of monetary assets resulting from a simple reclassification of deposits are partly huge. Ignoring this issue of the ECB's level data can lead to spurious shifts in the Divisia aggregate, compare Barnett and Gaekwad (2018). Following Darvas (2015), this problem can be solved using the ECB's transactions data, as defined in the regulation ECB/2013/33: "Financial transactions are computed by the ECB as the difference between stock positions at end-of-month reporting dates, from which the effect of changes that arise due to influences other than transactions is removed." For each monetary asset, these transactions can be used to compute the index of notional stock (European Central Bank 2012).

The rate of change of the notional stock index is a measure of growth in monetary assets volumes which arises purely from transactions and excludes valuation effects, including re-classifications, price fluctuations, changes in exchange rates, and other breaks in the series. Specifically, the index of the notional stock of a monetary asset $M_{i}$ in period $t$ is defined as

$$
I_{i t}=I_{i t-1}\left(1+\frac{T_{i t}}{M_{i t-1}}\right)
$$

where $T_{i t}$ is the transaction volume of asset $M_{i}$ in period $t$. The ECB selects a base value of 100 , which is not applicable for the Divisia index because the level of a component matters for the calculation of its weights. Following the procedure proposed in European Central Bank (2012), the base value is the level of the corresponding monetary asset in the base period January 2003. In the following, this index is applied to compute a Divisia aggregate that controls for re-classifications or other breaks unrelated to financial transactions.

The importance of using transaction data for the computation of a Divisia index is illustrated in Fig. 1 which shows the unadjusted level and the index of the notional stock of overnight deposits in the Netherlands. In December 2014, the Netherlands introduced a new reporting framework (De Nederlandsche Bank 2018) which had no 


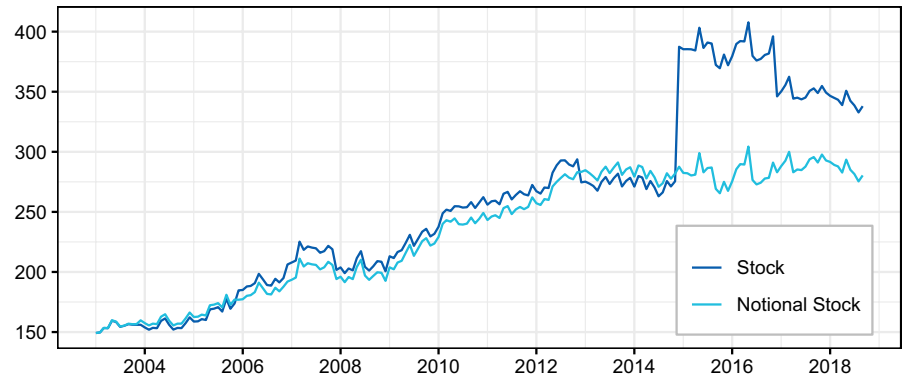

Fig. 1 Stock and index of notional stock for overnight deposits in the Netherlands. Notes In December 2014, the Netherlands introduced a new reporting framework which led to a large increase in overnight deposits (De Nederlandsche Bank 2018) (stock) that had no effects on the amount of liquidity. The Figure shows the unadjusted level data (stock) and the shift-adjusted index of notional stock of overnight deposits used in the computation of the Divisia aggregate

effects on transactions and the amount of liquidity. Yet, the reclassification implied a sharp increase in the level of overnight deposits. Note that this spurious realloaction of monetary assets would distort the year-to-year growth rates of the Divisia aggregate for a whole year. Similar level shifts due to reallocations of monetary assets can be seen in Ireland, Spain, Italy and France.

\subsection{Interest rates}

The country-specific own rates of return $\left(r_{i}\right)$ for the monetary assets are taken from the MFI interest rate statistics. ${ }^{4}$ In accordance with the literature, the interest rate for currency in circulation is assumed to be zero. Since there is no data available for the interest rates on outstanding amounts of overnight and 3-month deposits, we use the interest rates on new business. Missing values are imputed using a linear regression on the overnight deposit rate, see Barnett et al. (2013) and Fisher et al. (1993).

The choice of the benchmark rate $(R)$ is less obvious. In theory, the benchmark rate is the rate of return on a pure investment asset that provides no liquidity services on its own and is capital-certain. The assets sole purpose is the transfer of wealth from one period to the next, but such an asset does not exist in reality. User costs of zero would imply that the transaction services provided by the asset are free. In order to ensure that user cost of monetary assets are above zero $\left(\frac{R-r_{i}}{1+R}>0\right)$, the benchmark rate has to be strictly larger than the monetary assets own rates of return. Therefore, a natural candidate for the benchmark rate is the upper envelope of the monetary assets own rates of return plus a liquidity premium. Stracca (2004) includes a risk premium on 60 basis points while the Divisia indices provided by the Fed of St. Louis use 100 basis points, see Anderson and Jones (2011). Both studies

\footnotetext{
${ }^{4}$ European Central Bank (2017) gives a detailed description of the data and of the methods used to collect it.
} 


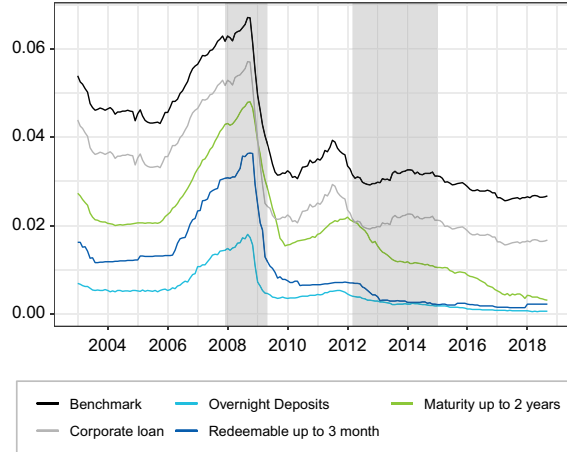

(a) Benchmark Rate $\left(R_{t}\right)$

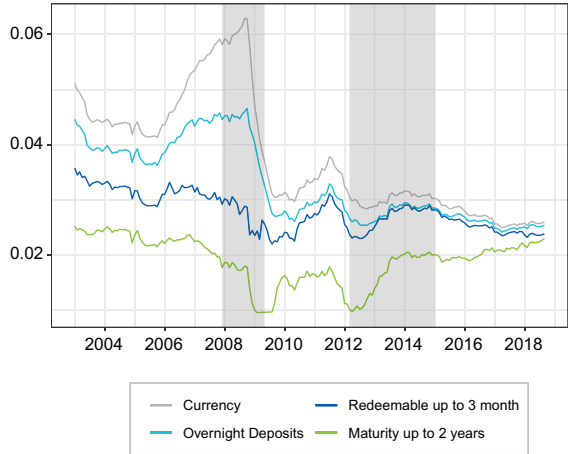

(b) User cost $\left(p_{t}\right)$

Fig. 2 Benchmark rate and user cost for Finland. Notes The user costs are calculated according to Eq. 3. The benchmark rate is defined as the upper envelope of the monetary assets own interest rates and the interest rate on loans up to 1 year maturity plus a liquidity premium of 100 basis points. The shaded areas indicate recession periods

conclude that Divisia growth rates are not sensitive to the magnitude of the liquidity premium.

The upper envelope approach with the liquidity premium is a practical but rather ad-hoc solution of the non-negativity problem of the benchmark rate. Therefore, the literature suggests alternative candidates for the benchmark rate which are closer related to economic theory. In particular, Darvas (2015) approximates the benchmark rate by bank debt with longer maturities than those included in the monetary aggregate. He finds them to be larger than the monetary assets own rates and accepts the downside that long-run bank debts are not risk-free. Barnett et al. (2013), following a suggestion from Offenbacher and Shemesh (2011), decide to stay in the risk-neutral setting and include the low risk corporate loan rate in the calculation of the upper envelope. This is because banks would not pay out a higher interest rate on short-term deposits than they earn with short-term loans. Barnett et al. (2013) only resolve to the upper envelope approach with liquidity premium of 100 basis point in periods where the corporate loan rate is not available.

In order to define an appropriate benchmark rate for the euro area, we follow Barnett and Gaekwad (2018) and consider the interest rate on loans up to 1 year maturity as the corporate loan rate. However, in contrast to the United States (Barnett et al. 2013) and Israel (Offenbacher and Shemesh 2011), corporate loan rates in the euro area do not always exceed the monetary assets own rates. Thus, a liquidity premium of 100 basis points is added to the upper envelope of the own rates and the loan rate to ensure positive user costs.

In order to illustrate our approach for defining the benchmark rate, Fig. 2 displays the interest rates and the implied user cost for Finland. In normal times, the upper envelope of the interest rates is the corporate loan rate implying that the benchmark rate is the loan rate plus 100 basis points. For several months in 2009, however, the corporate loan rate was below the rate for longer-term deposits. In this period, the longer-term deposit rate is the upper envelope and, thus, the Finnish benchmark rate 
is computed as the longer-term deposit rate plus 100 basis points. While Barnett and Gaekwad (2018) add the liquidity premium only for those periods where the loan rate does not exceed the own rates, we find it more plausible to add the liquidity premium in each period.

We also calculate Divisa indices using alternative measures of the liquidity premium. Particularly, we followed Barnett (2003) and implemented a time-varying liquidity premium proxied by the spread between the yields of a 10 year BBB rated corporate and a long-term government bond. In line with Stracca (2004) and Anderson and Jones (2011), the liquidity premium has no important impact on our results. The correlation between the Euro area Divisia indices based on the constant and the time-varying premium is 0.99 , see Fig. 14 in the "Appendix".

\section{Divisia monetary aggregates at the country level}

Divisia aggregates depend on both, interest rates and the composition of monetary assets. Before we further aggregate to the EA-12 Divisia index, this section investigates the behavior of the various components of the M2 Divisia aggregate at the country level. The aim of the analysis is twofold. On the one hand, we explore when and why one should expect economically relevant differences between the behavior of Divisia and simple sum monetary aggregates within a country. On the other hand, we are interested in the main drivers of heterogeneity in monetary developments, i.e. when and why the behavior of country-specific Divisia aggregates differs across EA-12 countries.

\subsection{User cost}

If user cost were always identical for all monetary assets, growth rates of Divisia and corresponding simple sum aggregates would also be identical. As a result, there would be no additional information content of Divisia aggregates. Therefore, it is worth emphasizing that the user cost of different monetary assets significantly differ within and across EA-12 countries, compare Fig. 9 in the "Appendix".

As the benchmark rate is the same for all monetary assets within a country, higher own rates imply lower user cost. Since the own rate of currency is zero, the user cost of currency $\left(\frac{R_{t}}{1+R_{t}}\right)$ is always close to the benchmark rate. Likewise, user cost of deposits have converged to the benchmark rate in all EA-12 countries in the current low-interest-rate environment. Figure 9 shows that user cost can immensely differ across EA-12 countries. As a referee remarked, this may reflect financial market fragmentation and institutional particularities, such as administrated rates on deposit accounts. However, a common feature of all EA-12 countries is the pronounced dip in the user cost of longer-term deposits in the aftermath of the Lehman breakdown in 2008. During the European debt and banking crisis user cost particularly increase in the countries most affected by the crisis, like Greece, Italy, Spain, and Portugal. 


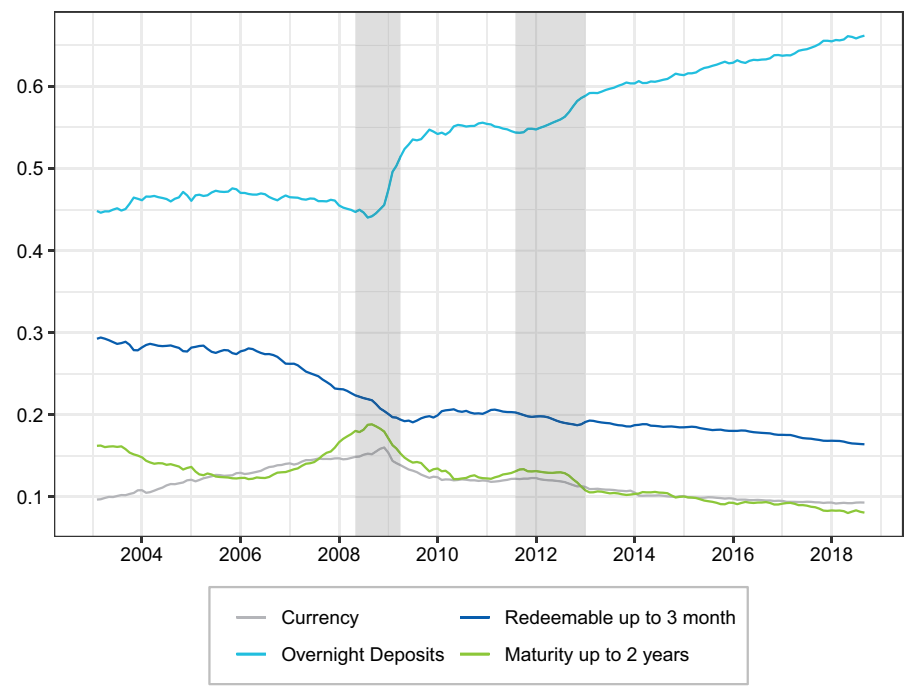

Fig. 3 Expenditure shares in Germany. Notes The weight of a monetary asset used in the computation of the Divisia aggregate depends on its expenditure share, compare Equation (2) in Sect. 2.2. The Figure shows the expenditure shares of the monetary assets included in the German M2 Divisia aggregate. Shaded areas indicate recessions

\subsection{Expenditure shares}

The weight of the monetary asset's growth rate used in the computation of the Divisia aggregate depends on its expenditure share and thus on both, the user cost and the volume of the monetary asset. The expenditure shares significantly differ across the EA-12 countries, compare Fig. 11 in the "Appendix". The large and persistent differences in the level and the dynamics of expenditure shares strongly suggest that a euro area Divisia aggregate should not be based on the assumption of homogeneous member countries.

In spite of the significant heterogeneity across EA-12 countries, there are a few stylized facts about the size and evolution of expenditure shares that are worth noting. First, the expenditure share of currency in circulation is small (around $10 \%$ ) and rather stable over time for most of the EA-12 countries. The major exception is Greece where the currency weight has steadily increased since the outbreak of the financial crisis to more than 20\%. Second, for most of the EA-12 countries, overnight deposits take the highest expenditure share across monetary assets. The exception is now Belgium where the weights of 3-month deposits are particularly high. For most countries, however, the weight of overnight deposits range between 50\% (France) and 70\% (Italy). Third, the expenditure share of overnight deposits is typically upward trending, particularly since the outbreak of the financial crisis, see e.g. Fig. 3 for the expenditures shares in Germany. The German example further illustrates the fourth stylized fact, namely that major shifts in expenditure shares are related to recession periods. 


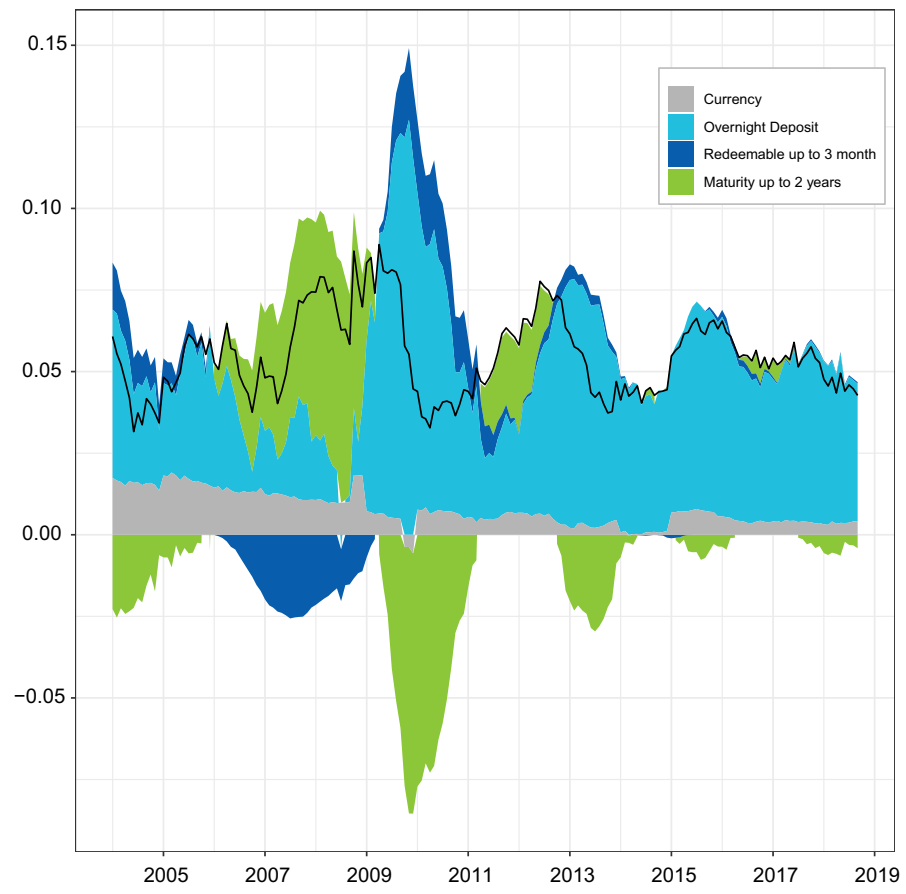

Fig. 4 Components contribution in Germany. Notes The Figure shows the annual growth rate of the German M2 Divisia aggregate and how the four types of monetary assets contribute to it

For all EA-12 countries, the nearly constant expenditure share of currency implies an inverse relationship between the expenditure share of overnight deposits and the weight of the two remaining types of longer-term deposits, i.e. 3-month deposits and deposits with a maturity up to 2 years. The relative importance of both types of longer-term deposits varies remarkably across EA-12 countries. In some countries, including e.g. Germany and Spain, the expenditure share of 3-month deposits is large but decreasing. In other countries, including Austria, Greece and Portugal, 3 months deposits play no role such that their weight in the Divisia aggregate is virtually zero.

\subsection{Monetary components and Divisia growth}

The analysis of expenditure shares provided insights into the relative importance of monetary components for the Divisia aggregate. Expenditure shares, however, cannot reveal the absolute importance of a monetary asset, i.e. to what extent an observed change in the Divisia aggregate can be attributed to the underlying monetary components. To that aim, we adopt the approach of the Center for Financial Stability (CFS) who regularly decomposes the contributions of the monetary components to the growth rate of the U.S. Divisia index. 


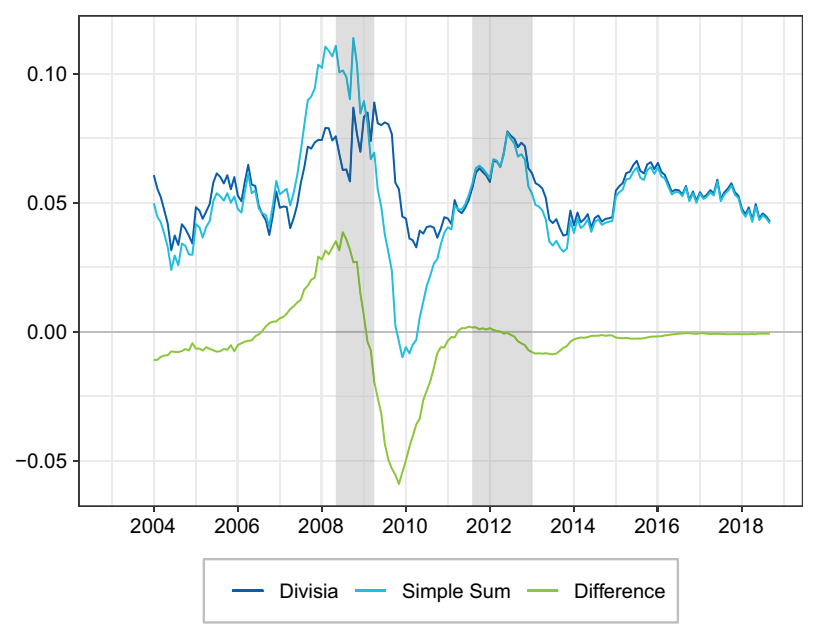

Fig. 5 Growth rates of Divisia and simple sum monetary aggregate in Germany. Notes The Figure shows the annual growth rates of the German M2 Divisia aggregate, its simple sum counterpart and the difference between the two growth rates. Shaded areas indicate recessions

We calculated the contributions of the four M2-related monetary assets to the growth of the Divisia aggregate for all EA-12 countries, see Fig. 13. In order to illustrate the usefulness of this tool, Fig. 4 shows how the various monetary assets have contributed to the annual growth rates of the German Divisia aggregate. Note that Fig. 4 sheds further light on the stylized facts derived for the expenditure shares. Specifically, Fig. 4 shows that (1) the contribution of currency to the growth rate of the Divisa index is small and stable. (2) Typically, the contribution of overnight deposits is by far the largest. (3) The dominant role of overnight deposits for the growth rate of the Divisia index is particular pronounced after the financial crisis. (4) During recessions, positive growth rates of overnight deposits are partly compensated by negative growth rates of longer-term deposits.

\subsection{The divergence between simple sum and Divisia aggregates}

In the following, we compare the country-specific Divisia aggregate with its simple sum counterpart. For each of the EA-12 countries, both monetary aggregates are shown in the Fig. 12.

Figure 5 shows the year-to-year growth rates of German M2, the M2 Divisia aggregate, and their divergence defined as the difference between the two growth rates. Similar to the other EA-12 countries, the growth rates of German M2 and its Divisia counterpart were very similar before 2007. In fact, M2 and the related Divisia aggregate conveyed broadly the same information about the liquidity situation in the economy in the rather calm pre-crisis period. However, Divisia and simple sum aggregates tend to grow very differently in more turbulent times. According to Fig. 4, the non-zero divergence around recessions can be explained by a reallocation of monetary assets from short- to longer-term deposits and vice versa. In line with 
Table 3 Country weights in the euro area Divisia index

\begin{tabular}{|c|c|c|c|c|c|c|c|c|c|c|c|c|}
\hline & \multicolumn{12}{|c|}{ Country } \\
\hline & AT & $\mathrm{BE}$ & $\mathrm{DE}$ & ES & FI & FR & GR & IE & IT & LU & NL & PT \\
\hline Weight & 2.6 & 3.4 & 25.1 & 15.8 & 1.6 & 21.1 & 3.4 & 1.3 & 17.7 & 0.2 & 5.1 & 2.7 \\
\hline
\end{tabular}

The Table shows the average expenditure shares (in \%) used as weights in the euro area wide M2 Divisia aggregate for each of the EA-12 countries, including Austria (AT), Belgium (BE), Finland (FI), France (FR), Germany (DE), Greece (GR), Ireland (IE), Italy (IT), Luxembourg (LU), the Netherlands (NL), Portugal (PT), Spain (ES). For more details on the derivation of expenditure share, see Eq. (5) in Sect. 2.3

Barnett and Chauvet (2011), the crisis-induced substitution from less liquid to more liquid monetary assets suggests that the difference between Divisia and simple sum growth rates could have a predictive content for recessions.

\section{The Divisia monetary aggregate for the euro area}

In the following section, we use the Divisia aggregates computed at the country level to compute the EA-12 Divisia monetary aggregate. The Divisia EA-12 aggregate is the weighted sum of the country-specific Divisia aggregates [compare Eq. (5)]. The weight of a country can be interpreted as its expenditure share.

Table 3 shows that the average expenditure shares of the EA-12 countries are very close to the corresponding shares in population or GDP, compare Table 2. As a consequence of the weighting scheme, euro area wide monetary aggregates will hardly respond to monetary developments in small countries like Greece. In the same vein, the very small weights of the new member countries (see Table 2) imply that monetary aggregates derived for the group of EA-12 countries should be very close to the full EA-19 measure.

The four largest countries (France, Germany, Italy, and Spain) account for almost $80 \%$ of the monetary unions total expenditure for monetary assets. The pre-dominant role of the big countries for the monetary developments of the whole euro area is reflected in their dominant impact on the growth rates of the EA-12 Divisia aggregate.

Figure 6 displays the annual growth rate of the Divisia EA-12 aggregate together with the growth contributions of France, Germany, Italy, and Spain. Apparently, the dynamics of the Divisia EA-12 aggregate can be attributed mostly to developments in these four countries. The contributions are mostly positive indicating that the amount of liquidity has typically increased. The notable exception is Spain where liquidity decreased in 2012, probably as a result of the European debt crisis. Note that the contributions of the four countries to the EA-12 Divisia aggregate have been very similar before the financial crisis. Since then, however, the monetary developments in Germany became more important for the EA-12 Divisia aggregate while the contribution of Spain has declined. 


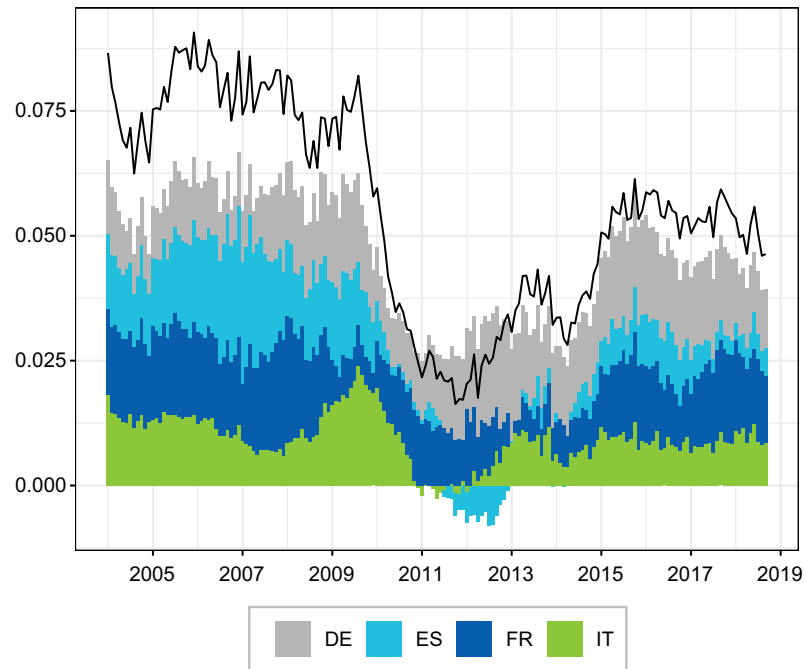

Fig. 6 Annual contribution of the largest countries. Notes The Figure shows the annual growth rate of the euro area M2 Divisia aggregate and how the four largest member countries Germany (DE), Spain (ES), France (FR), and Italy (IT) contribute to it

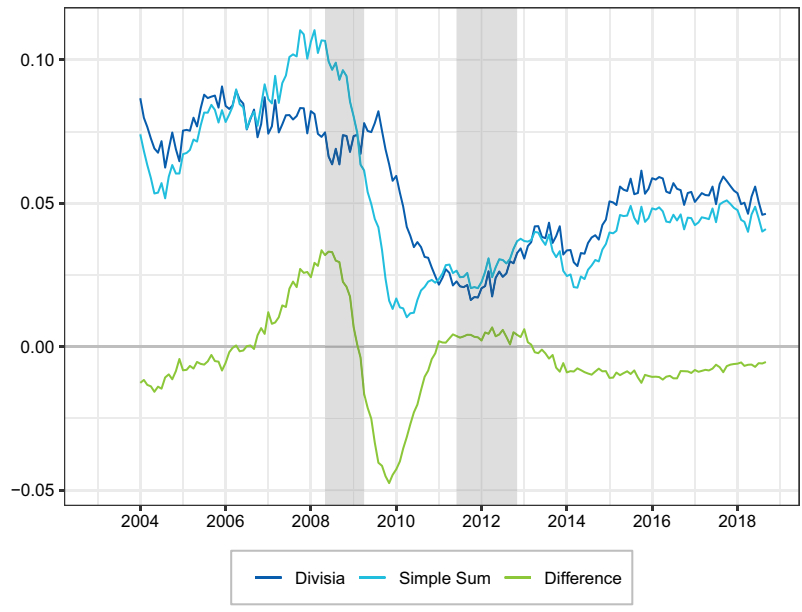

Fig. 7 Divisia and simple sum aggregates for the EA 12. Notes The Figure shows the annual growth rates of the euro area M2 Divisia aggregate, its simple sum counterpart and the difference between the two growth rates. The shaded areas indicate recession periods (color figure online)

Let us now compare the EA-12 M2 Divisia aggregate with its simple sum counterpart.

In accordance with the monetary developments in bulk of the EA-12 countries, Fig. 7 shows that the growth rates of the simple sum and the Divisia aggregate differ particularly around the great recession. In line with the analysis of individual 


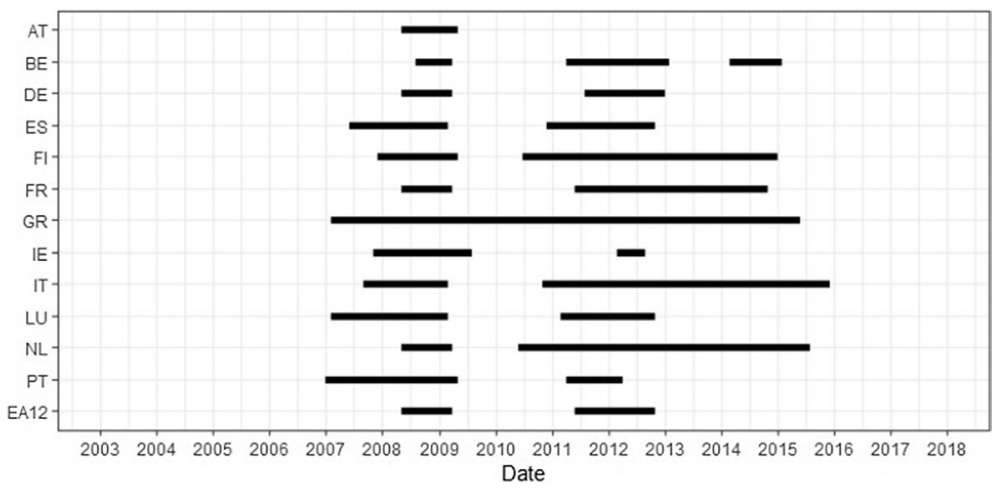

Fig. 8 Recessions in the EA-12 countries. Notes The Figure shows for each EA-12 country the monthly recession indicator based on the country's index of industrial production. For further explanation, see e.g. Artis et al. (1997) and Footnote 5

countries, the simple sum aggregate of the EA-12 area overestimates the change in liquidity services in the run-up to the crisis when monetary assets shifted from overnight to longer-term deposits. In contrast, the amount of liquidity is clearly underestimated by the simple sum aggregate from about 2009 until 2011 when these shifts in money holdings were reversed. The recession in the euro area around 2012 was much weaker than the great recession, particularly for the big countries. This may explain why the difference between the growth rates of euro area simple sum and Divisia aggregates is less pronounced in that period.

\section{Divisia aggregates and recessions in euro area countries}

In accordance with the observation of Barnett and Chauvet (2011) for the U.S., our analysis suggested that the divergence between the Divisia aggregate and its simple sum counterpart could be a useful predictor of recessions for the EA-12 countries. In this section, we aim to investigate the predictive content of the divergence for recessions more closely.

The CEPR euro area Business Cycle Dating Committee publishes only a common European economic cycle. While there might be a convergence of business cycles in the long-run, recession periods in the EA-12 countries might not fully coincide in our sample period. Following e.g. Artis et al. (1997), we define a country-specific recession indicator based on the country's index of industrial production provided by Eurostat. ${ }^{5}$ Figure 8 shows that the timing and the length of recession

\footnotetext{
5 Specifically, we define recession periods using a 7-month moving average of industrial production while peaks and troughs of the business cycles are identified as the absolute highest or lowest points within 24 months. Note that our results are robust with respect to alternative methods of defining recession dates. "Appendix 3" shows the results obtained using the OECD leading indicators.
} 
periods differ significantly between EA-12 countries, particularly in the aftermath of the financial crisis.

In the tradition of Estrella and Mishkin (1998), we use a probit model to estimate the predictive power of the Divisia aggregates with respect to future recessions. Following e.g. Borio et al. (2018), we employ a pooled panel probit model in order to exploit the panel dimension of our data set. The variable being predicted is the country-specific recession indicator $Y_{i, t}$ that equals one if country $i$ is in a recession in period $t$ and zero otherwise. The model is defined in reference to a theoretical linear relationship of the form

$$
y_{i, t}^{*}=\beta^{\prime} x_{i, t-h}+\varepsilon_{i, t}
$$

where the unobservable $y^{*}$ determines the occurrence of a recession, $h$ is the length of the forecast horizon, $\varepsilon$ is a normally distributed error term, $\beta$ is a vector of coefficients, and $x$ is a set of predictors, including a constant. The observable recession indicator $Y_{i, t}$ is assumed to be one if $y_{i, t}^{*}>0$ and zero otherwise. In a probit model, the estimated equation is

$$
\operatorname{Prob}\left(Y_{i, t}=1\right)=\Phi\left(\beta^{\prime} x_{i, t-h}+\varepsilon_{i, t}\right)
$$

where $\Phi$ denotes the cumulative normal distribution function.

Following e.g. Berge and Jordá (2011), we consider the Area Under the Receiver Operating Characteristic (AUROC) as a measure of a model's signalling quality. For all possible cut-off-values of the probit model, the ROC curve maps out the fraction of correctly predicted recessions versus the fraction of false alarms. The larger the AUROC, the higher the signalling quality of a model. Specifically, the AUROC of a perfect model equals one, while an uninformative model (equivalent to flipping a coin) has an AUROC of 0.5.

In the first step, we estimate a benchmark probit model that ignores monetary aggregates and only includes information from long- and short-term interest rates, i.e. for each EA-12 country the 10 year government bond rate $\left(R_{i, t-h}^{L}\right)$ and the 3-month money market rate $\left(R_{i, t-h}^{S}\right)$ provided by the OECD. Recently, the wellestablished predictive content of the spread between long- and short-term interest rates $\left(S P=R^{L}-R^{S}\right)$ has been reconfirmed by Goodhart et al. (2019) for the UK. Following Goodhart et al. (2019), the benchmark model additionally controls for the level of the long term interest rate. The upper part of Table 4 summarizes our estimation results obtained for the benchmark model. In accordance with the empirical literature, the presented t-statistics show that the predictive content of the spread for recessions is significant and plausibly signed for all forecasting horizons. The usefulness of the term spread is also reflected in AUROCs above 0.5.

In the second step, we replaced the term spread by the divergence between the growth rates of the M2 Divisia aggregate and its simple sum counterpart 
Table 4 Predicting recessions in the euro area: results from a panel probit analysis

\begin{tabular}{|c|c|c|c|c|c|}
\hline & \multicolumn{5}{|c|}{$\mathrm{h}=$ month ahead } \\
\hline & 3 & 6 & 9 & 12 & 18 \\
\hline \multicolumn{6}{|c|}{$\operatorname{Pr}\left(Y_{i, t}=1\right)=\Phi\left(\beta_{0, h}+\beta_{1, h} S P_{i, t-h}+\beta_{2, h} R_{i, t-h}^{L}\right)$} \\
\hline$t$-stat $\beta_{1}$ & $-6.78 * * *$ & $-6.75 * * *$ & $-5.14 * * *$ & $-3.60 * * *$ & $-1.77 *$ \\
\hline$t$-stat $\beta_{2}$ & $12.01 * * *$ & $10.84 * * *$ & $8.70^{* * *}$ & $6.43 * * *$ & $3.67 * * *$ \\
\hline Pseudo $R^{2}$ & 0.096 & 0.106 & 0.099 & 0.085 & 0.054 \\
\hline AUROC & 0.6955 & 0.6999 & 0.6921 & 0.6773 & 0.6359 \\
\hline \multicolumn{6}{|c|}{$\operatorname{Pr}\left(Y_{i, t}=1\right)=\Phi\left(\beta_{0, h}+\beta_{2, h} R_{i, t-h}^{L}+\beta_{3, h} D I V_{i, t-h}\right)$} \\
\hline$t$-stat $\beta_{2}$ & $18.83 * * *$ & $10.03 * * *$ & $9.43 * * *$ & $8.10 * * *$ & $6.70 * * *$ \\
\hline$t$-stat $\beta_{3}$ & $9.96^{* * *}$ & $6.19 * * *$ & $4.19 * * *$ & $2.84 * * *$ & 0.64 \\
\hline Pseudo $R^{2}$ & 0.150 & 0.136 & 0.105 & 0.077 & 0.043 \\
\hline AUROC & 0.7429 & 0.7487 & 0.7315 & 0.7019 & 0.6440 \\
\hline \multicolumn{6}{|c|}{$\operatorname{Pr}\left(Y_{i, t}=1\right)=\Phi\left(\beta_{0, h}+\beta_{1, h} S P_{i, t-h}+\beta_{2, h} R_{i, t-h}^{L}+\beta_{3, h} D I V_{i, t-h}\right)$} \\
\hline$t$-stat $\beta_{1}$ & -0.28 & $-2.33 * *$ & $-2.81 * * *$ & $-2.63 * * *$ & $-2.02 * *$ \\
\hline$t$-stat $\beta_{2}$ & $5.64 * * *$ & $6.31 * * *$ & $6.10 * * *$ & $5.27 * * *$ & $3.81 * * *$ \\
\hline$t$-stat $\beta_{3}$ & $7.79 * * *$ & $4.73 * * *$ & $3.06 * * *$ & $1.70^{*}$ & -0.85 \\
\hline Pseudo $R^{2}$ & 0.151 & 0.140 & 0.114 & 0.088 & 0.055 \\
\hline AUROC & 0.7427 & 0.7417 & 0.7177 & 0.6907 & 0.6346 \\
\hline
\end{tabular}

The Table shows measures of fit and t-statistics for pooled panel probit models with and without the divergence between the growth rate of M2 Divisia and its simple sum counterpart. $S P$ denotes the spread between the long- and short-term interest rate, $R^{L}$ is the 10 year government bond rate and $D I V$ is the divergence between the growth rate of two monetary aggregates. t-statistics are based on Newey-West standard errors with a autocorrelation length of $h-1$. $^{* *} / /^{* *} / *$ indicate significance at the 1-/5-/10- percent level

$\left(D I V_{i, t-h}\right)$. According to both the pseudo $R^{2}$ and the AUROC measure, the results suggest that Divisia monetary aggregates contain even more useful information for the prediction of recessions than the term spread, particularly for forecast horizons up to 9 months. Finally, the lower part of Table 4 provides the results of the probit model that includes both predictive variables. Note that the improvements obtained by adding the term spread to the Divisia divergence model are virtually negligible. Accordingly, monitoring the development of the Divisia divergence is not only useful for predicting recessions, but it also captures the information contained in the term spread. 


\section{Conclusions}

This paper introduces a Divisia monetary aggregate for the EA-12 countries. Advancing on earlier contributions, the new Divisia data account for the heterogeneity of the euro area. We show that user cost and the composition of monetary assets have differed remarkably across euro area countries, particularly since the run-up to the financial crisis. In line with El-Shagi and Kelly (2019) our findings demonstrate the importance of country-specific data for the analysis of macroeconomic developments in the euro area. Using a panel probit analysis, we confirm that Divisia aggregates help to predict recessions in euro area countries. In particular, we find evidence in favor of Barnett and Chauvet's (2011) conjecture about the specific information content of the divergence between Divisia and simple sum monetary aggregates.

The focus of the current paper is on euro area Divisia aggregates that correspond to the simple sum aggregate M2 and, thus, to a relatively narrow definition of money. For the United States, Dery and Serletis (2020) showed that the picture of the liquidity situation in the economy becomes more complete the broader the set of monetary assets that is accounted for. ${ }^{6}$ This suggests that the analysis of broader Divisia indices could be a promising route for future research on the information content of monetary aggregates and their role for the transmission process of monetary policy.

\section{Funding Open Access funding provided by Projekt DEAL.}

Open Access This article is licensed under a Creative Commons Attribution 4.0 International License, which permits use, sharing, adaptation, distribution and reproduction in any medium or format, as long as you give appropriate credit to the original author(s) and the source, provide a link to the Creative Commons licence, and indicate if changes were made. The images or other third party material in this article are included in the article's Creative Commons licence, unless indicated otherwise in a credit line to the material. If material is not included in the article's Creative Commons licence and your intended use is not permitted by statutory regulation or exceeds the permitted use, you will need to obtain permission directly from the copyright holder. To view a copy of this licence, visit http://creativecommons.org/licen ses/by/4.0/.

\section{Appendix 1: Datasources}

See Table 5.

\footnotetext{
${ }^{6}$ Particularly, credit cards are becoming an increasingly important source of deferred payment services. Barnett and Su (2019) showed how to include those services into Divisia monetary aggregates.
} 


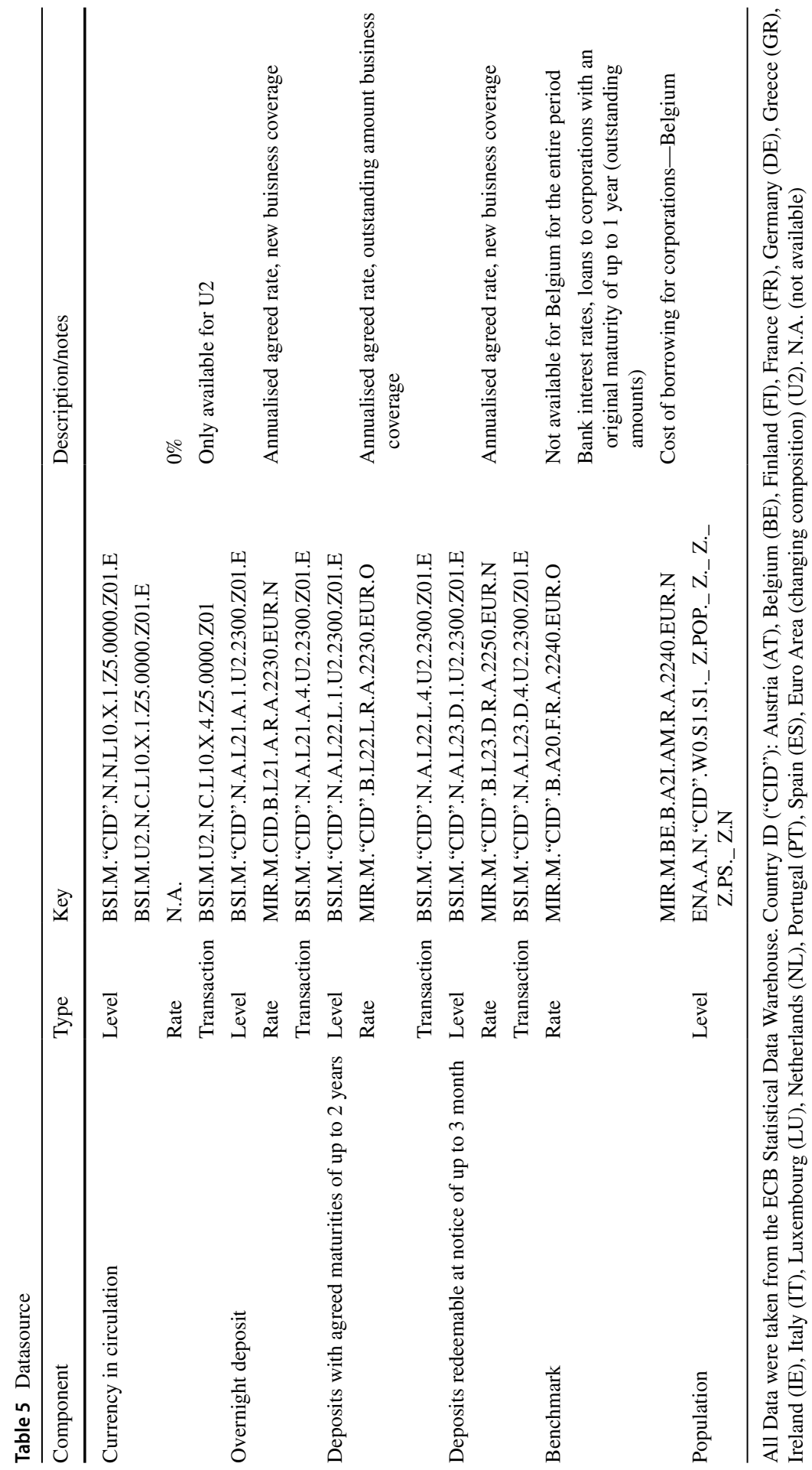




\section{Appendix 2}

See Figs. 9, 10, 11, 12.

(a) Austria

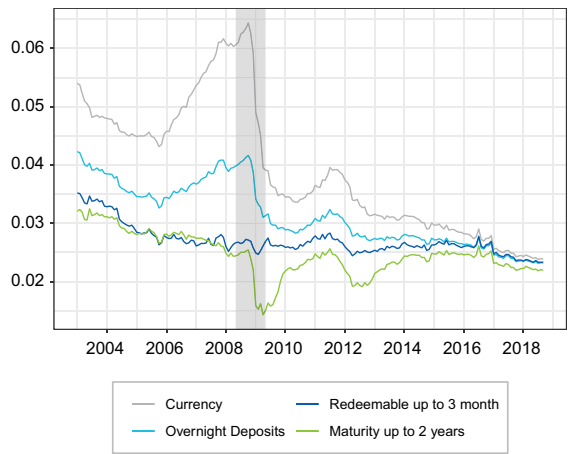

(c) Germany

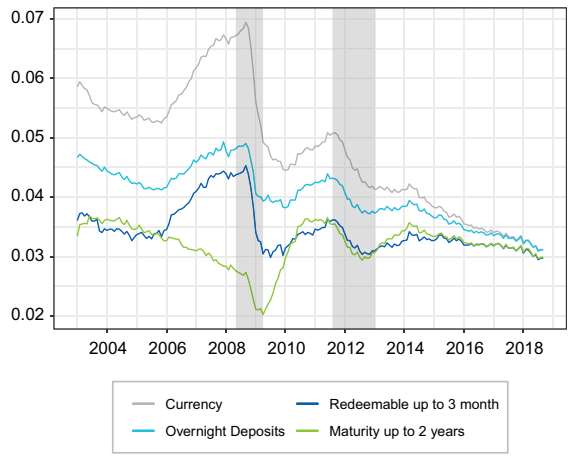

(e) Finland

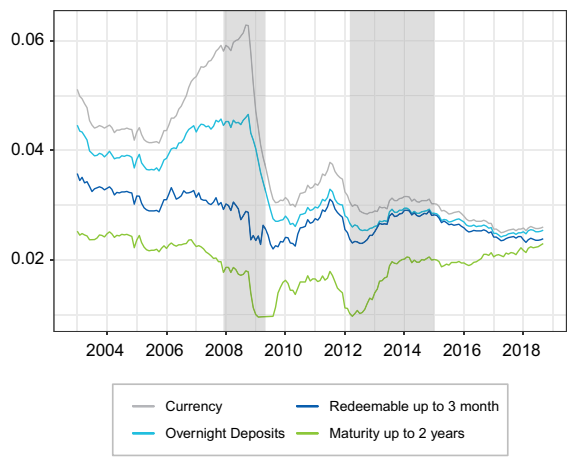

Fig. 9 The user costs for each EA-12 country (b) Belgium

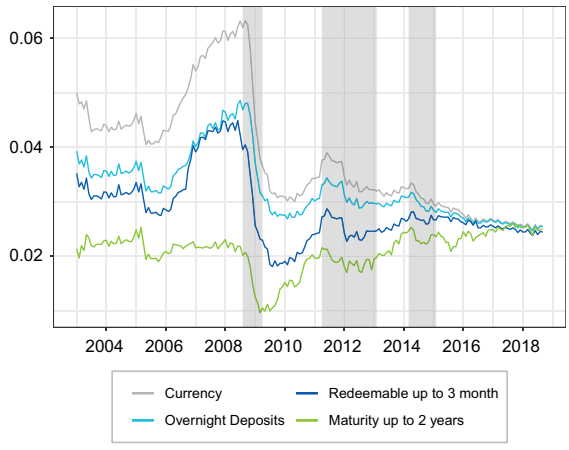

(d) Spain

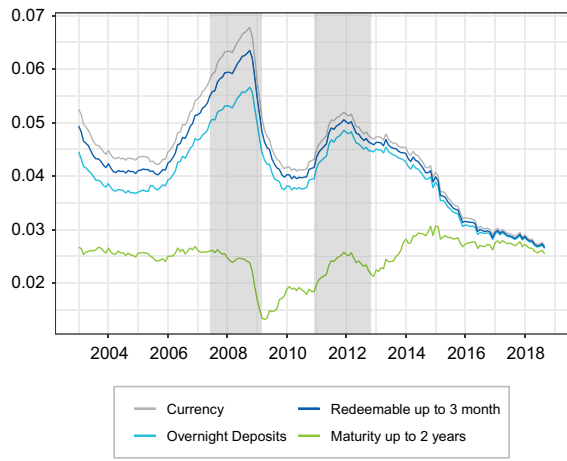

(f) France

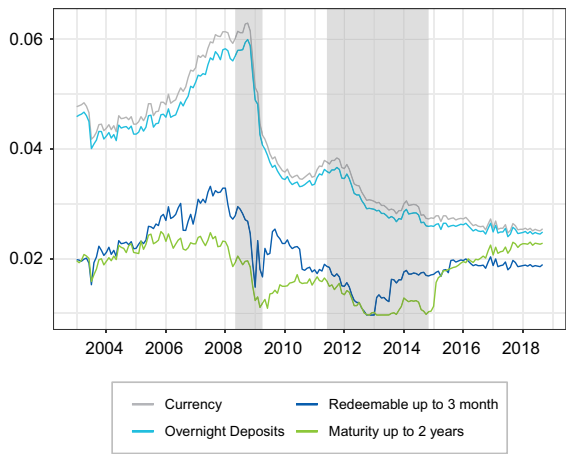


(g) Greece

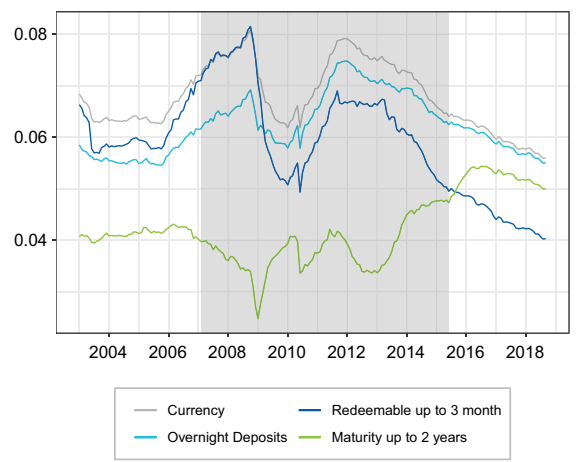

(i) Italy

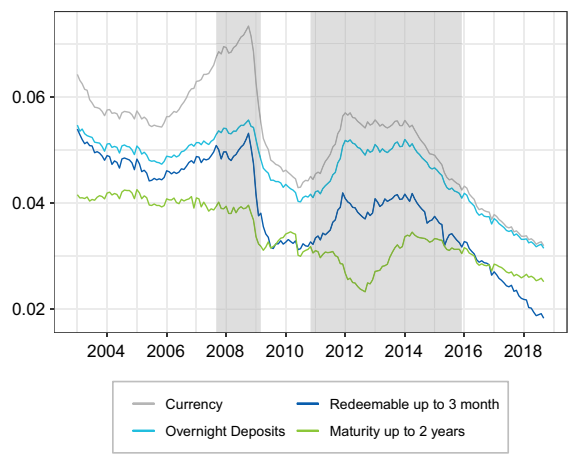

(k) The Netherlands

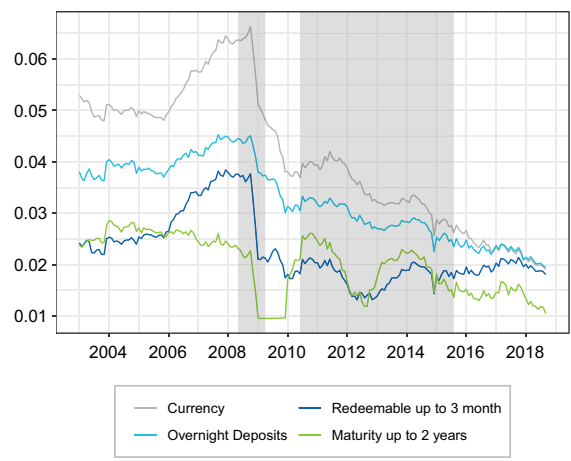

Fig. 9 (continued) (h) Ireland

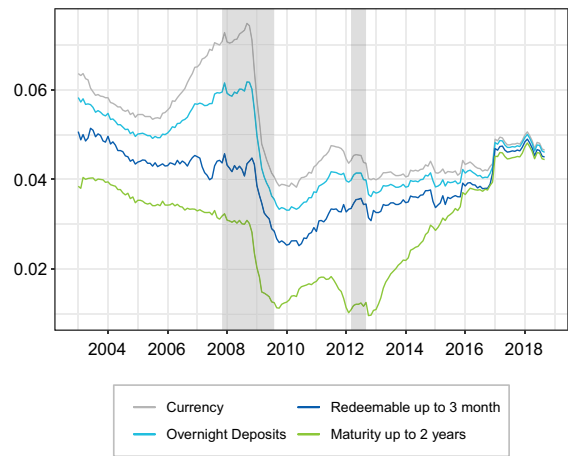

(j) Luxembourg

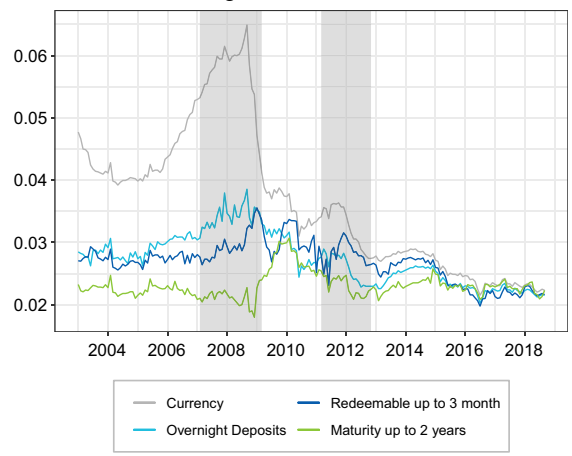

(l) Portugal

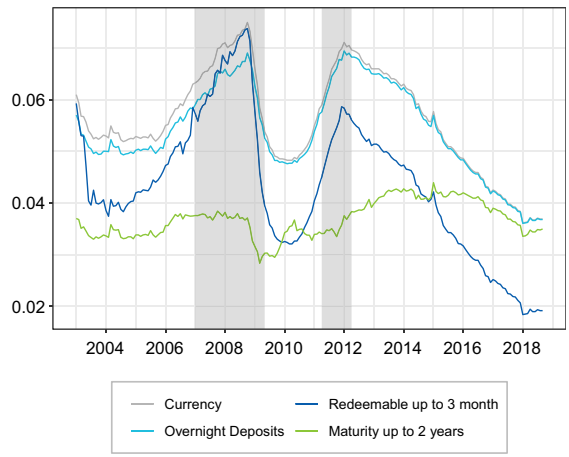


(a) Austria

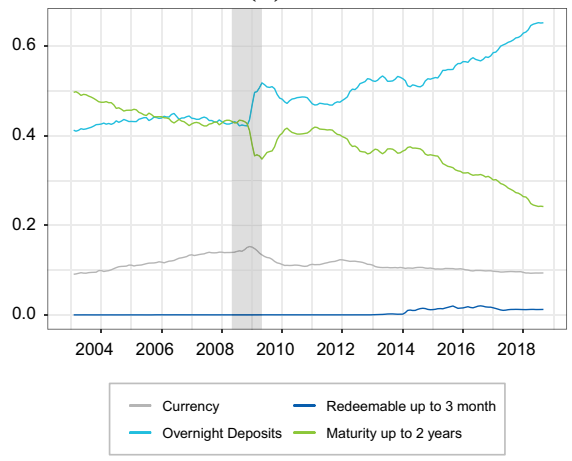

(c) Germany

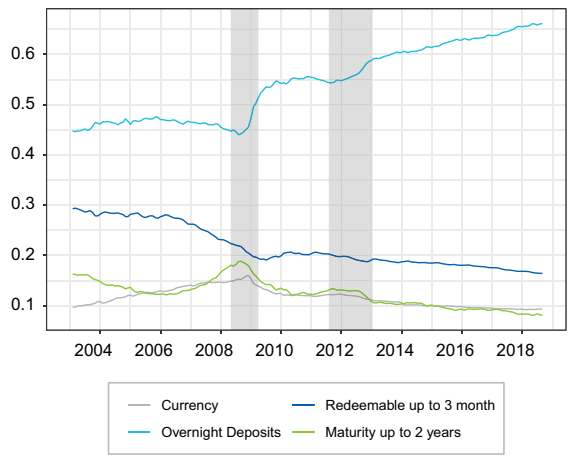

(e) Finland

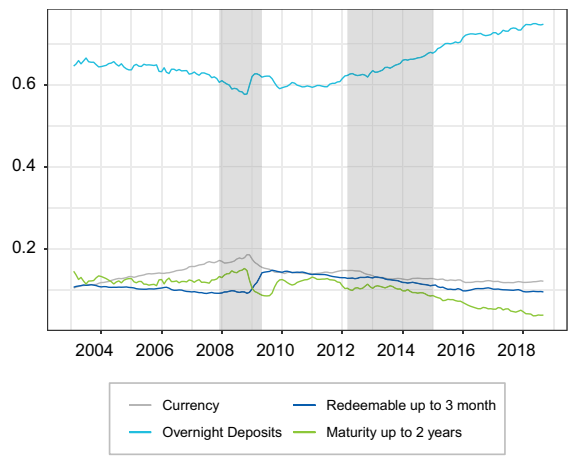

(b) Belgium

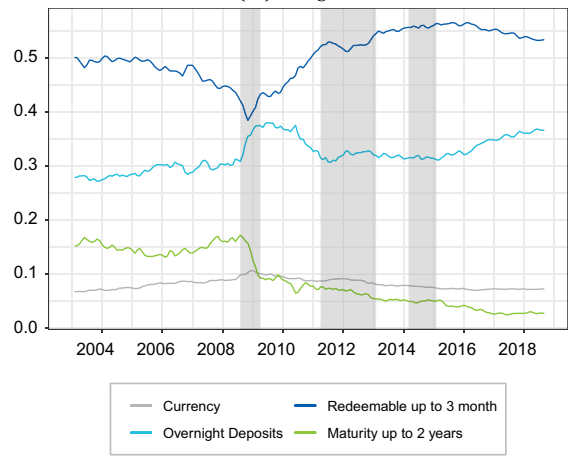

(d) Spain

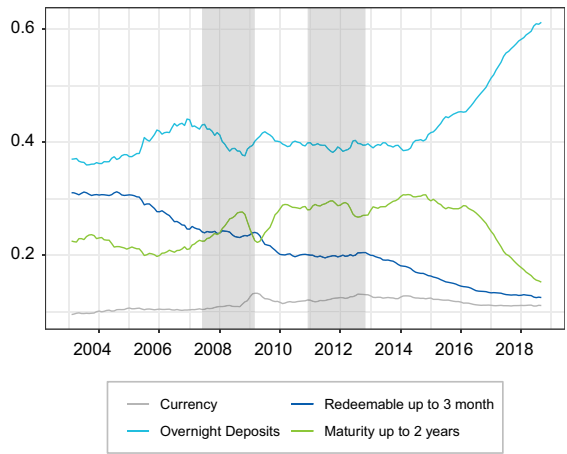

(f) France

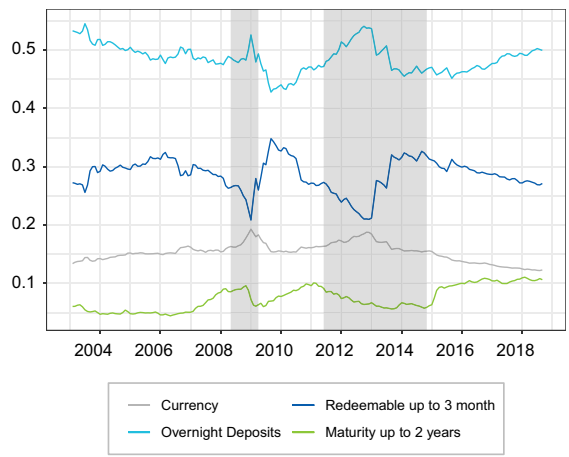

Fig. 10 The expenditure shares for each EA-12 country 
(g) Greece
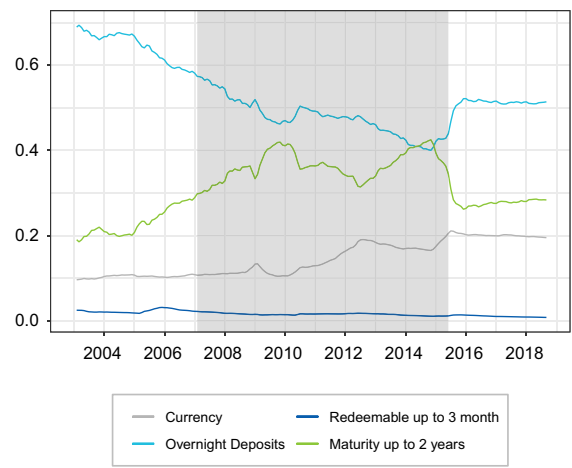

(i) Italy

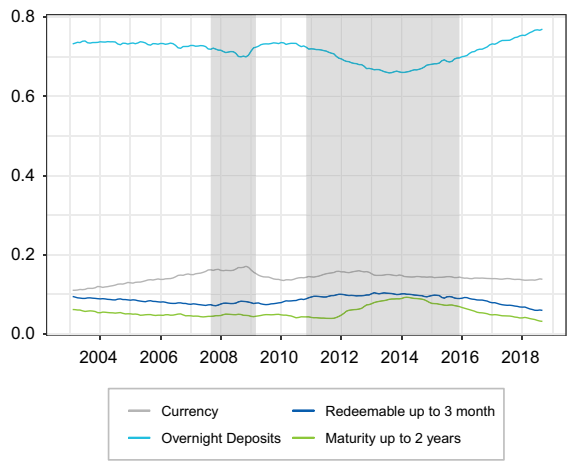

(k) The Netherlands

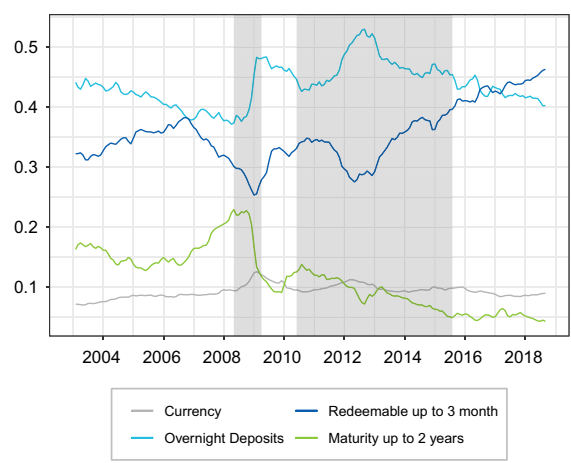

Fig. 10 (continued) (h) Ireland

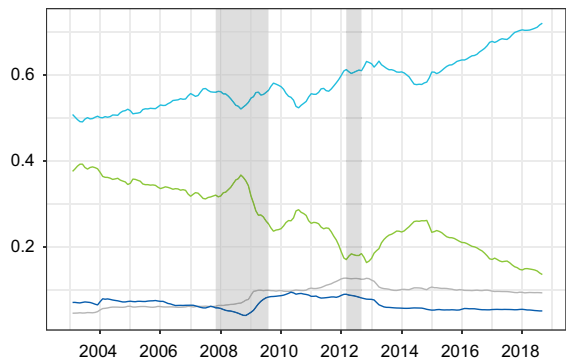

\begin{tabular}{|ll|}
\hline - Currency & Redeemable up to 3 month \\
- Overnight Deposits & - Maturity up to 2 years \\
\hline
\end{tabular}

(j) Luxembourg

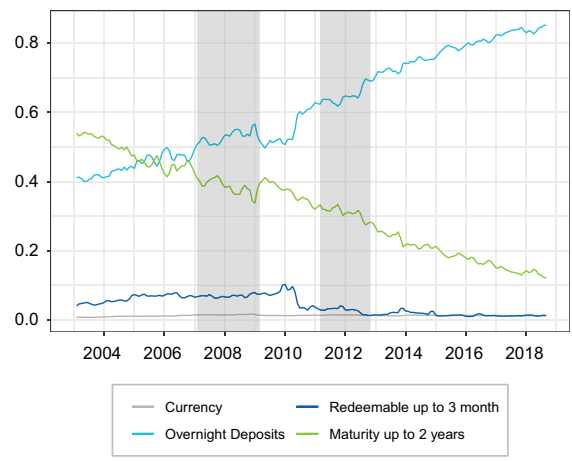

(l) Portugal

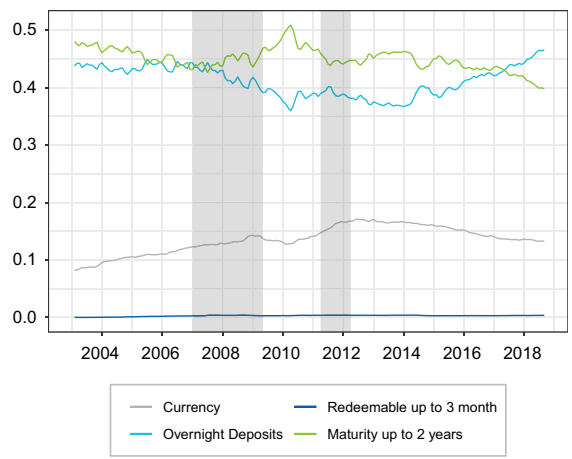


(a) Austria

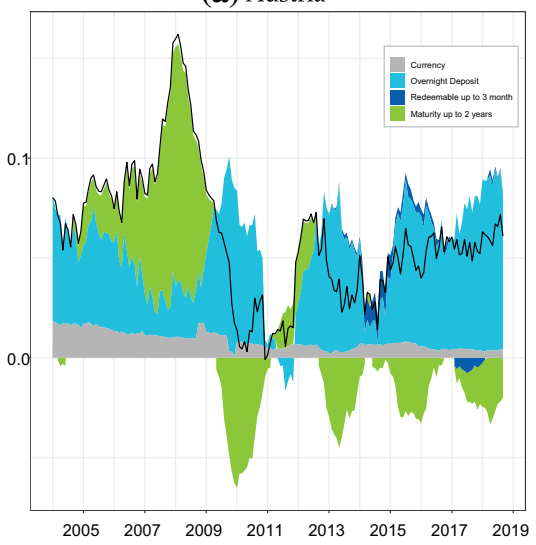

(c) Germany

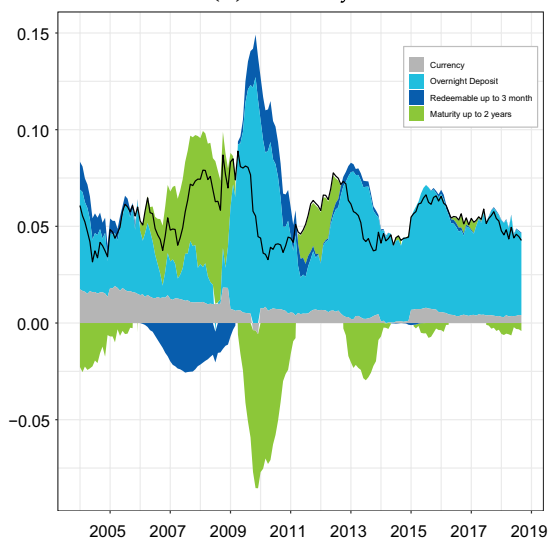

(e) Finland

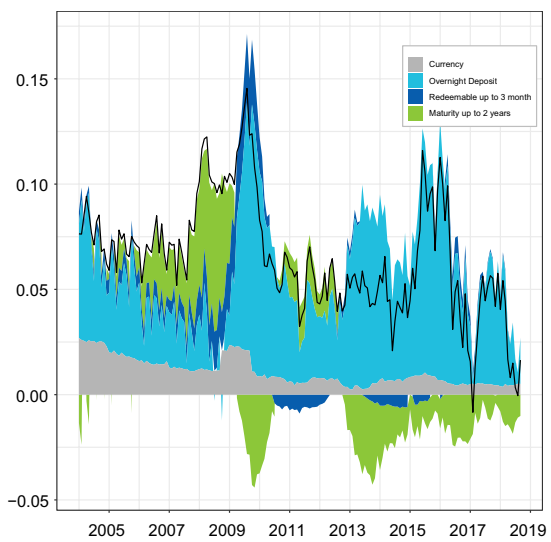

(b) Belgium

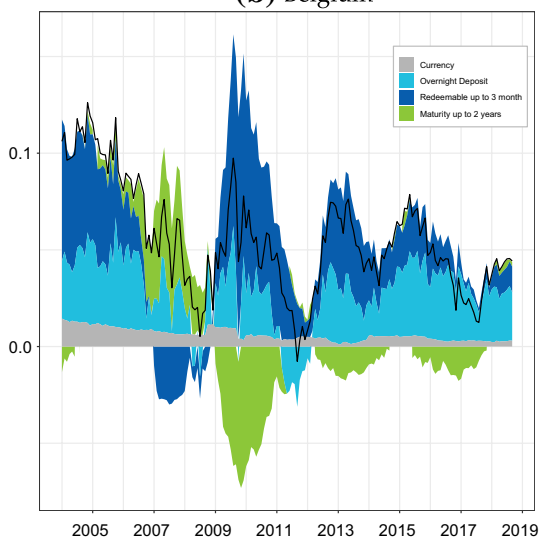

(d) Spain

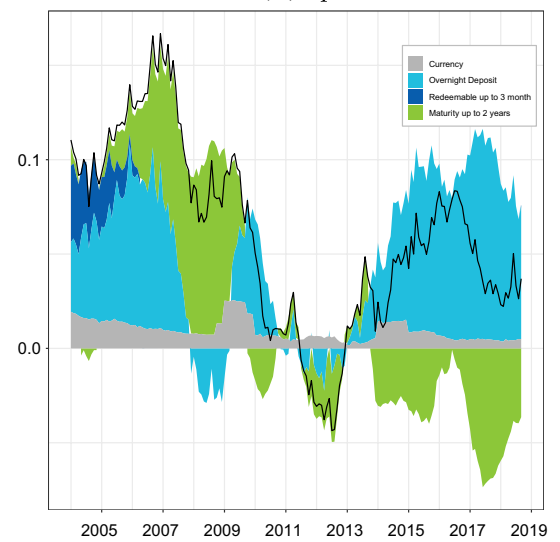

(f) France

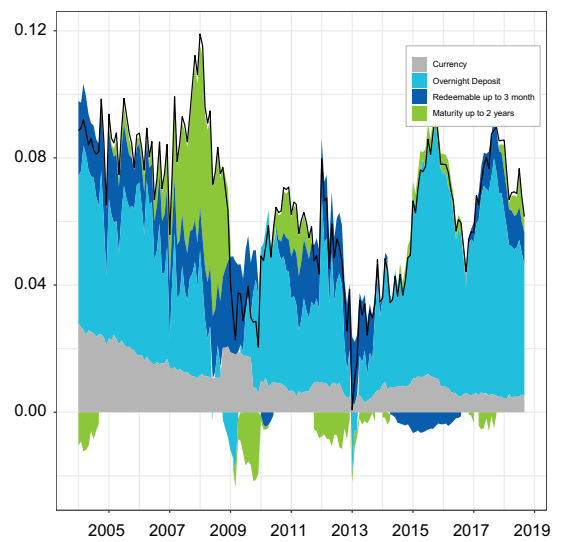

Fig. 11 The contributions of the monetary assets to the Divisia aggregate growth for eachEA-12 country 
(g) Greece

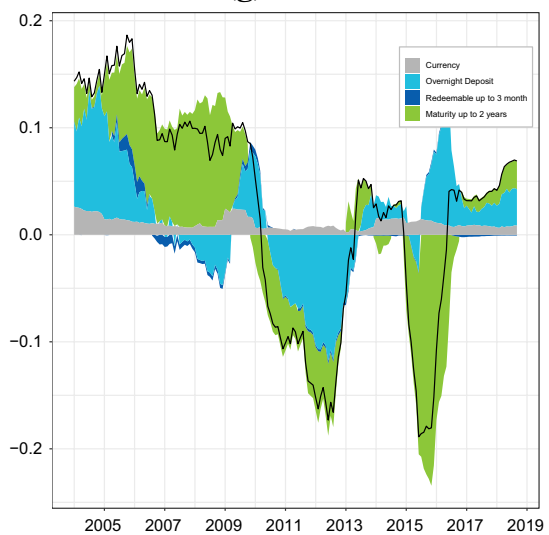

(i) Italy

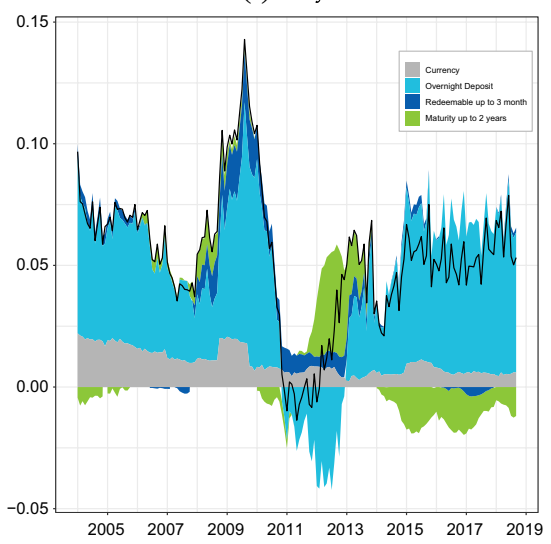

(k) The Netherlands

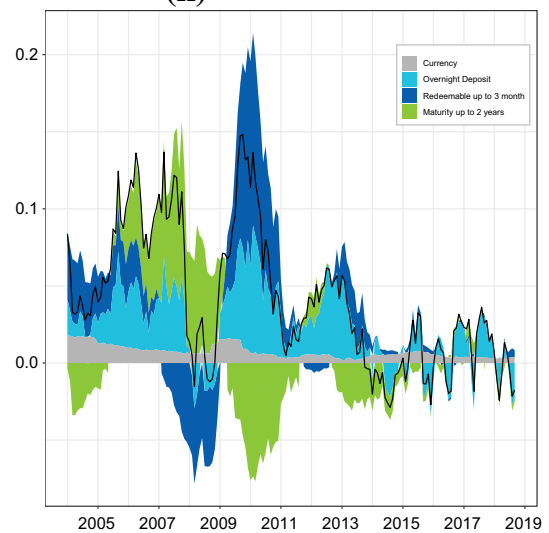

(h) Ireland

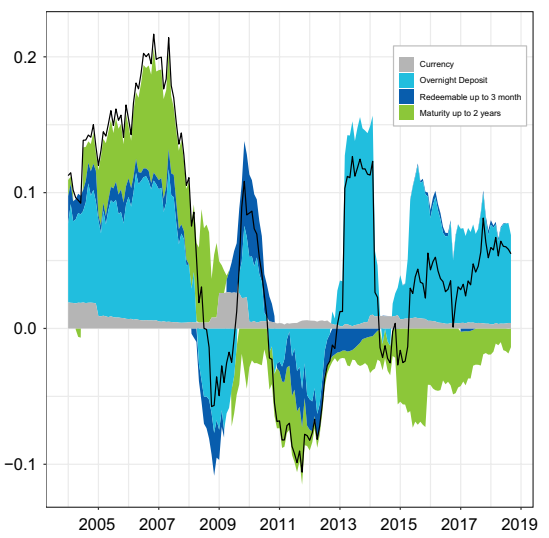

(j) Luxembourg

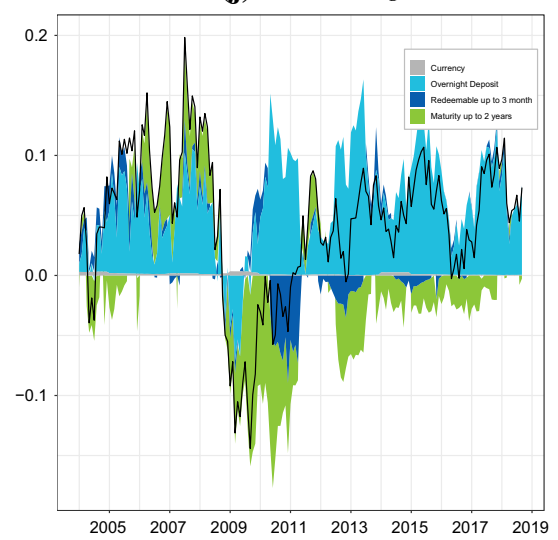

(l) Portugal

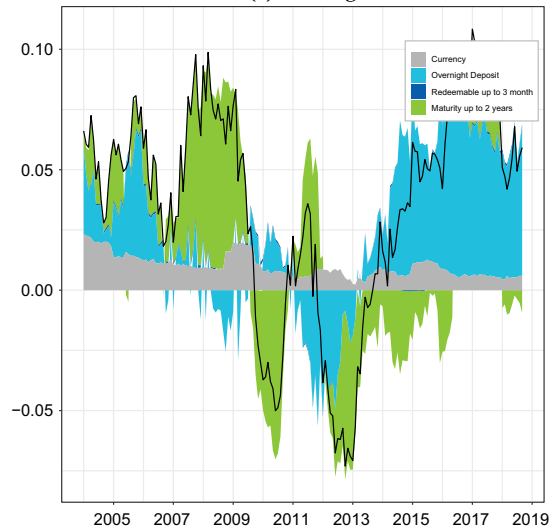

Fig. 11 (continued) 
(a) Austria

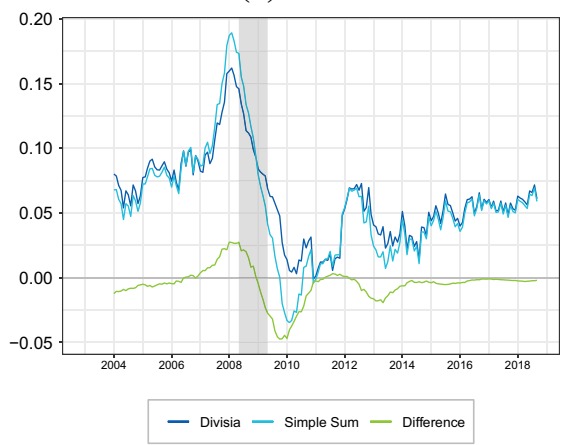

(c) Germany

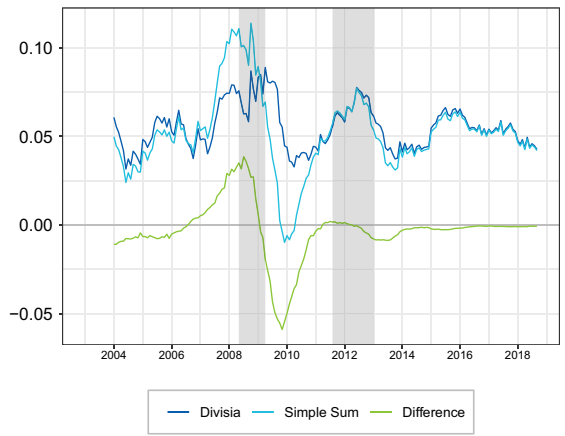

(e) Finland

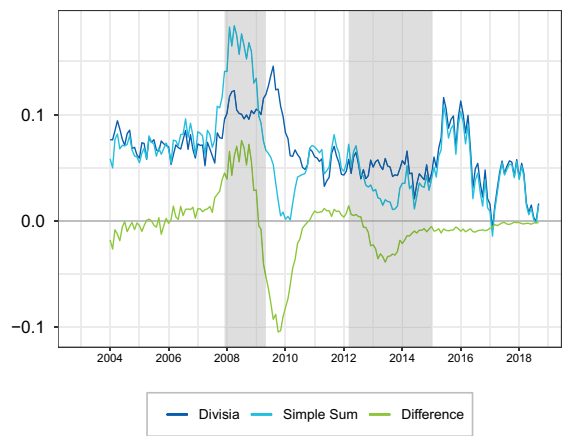

(b) Belgium

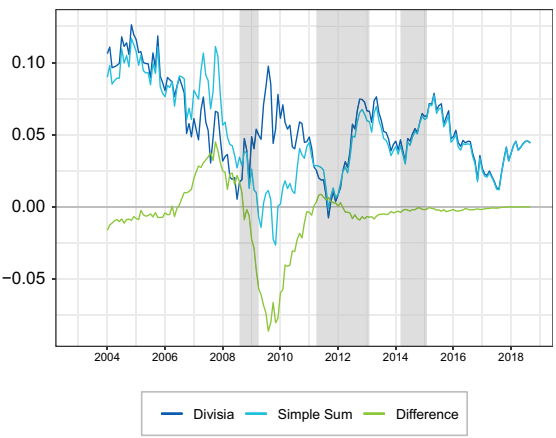

(d) Spain

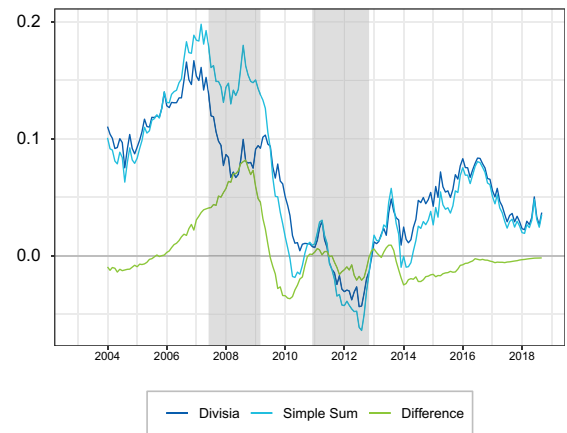

(f) France

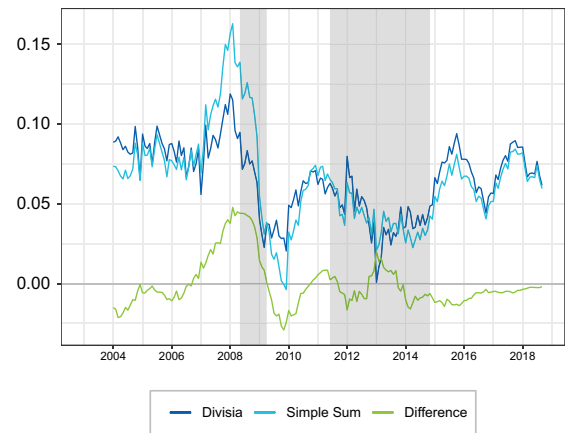

Fig. 12 The growth rates of Divisia and simple sum monetary aggregate for each EA-12country 
(g) Greece

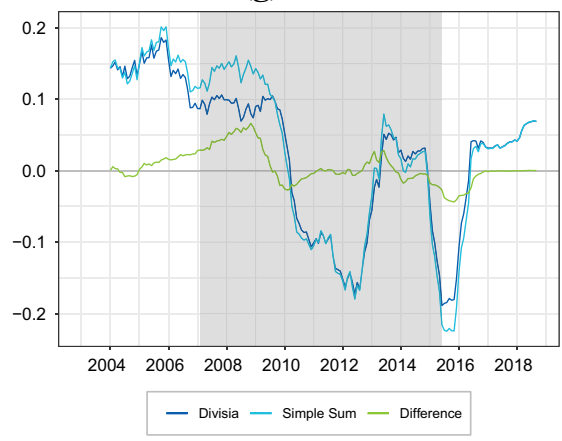

(i) Italy

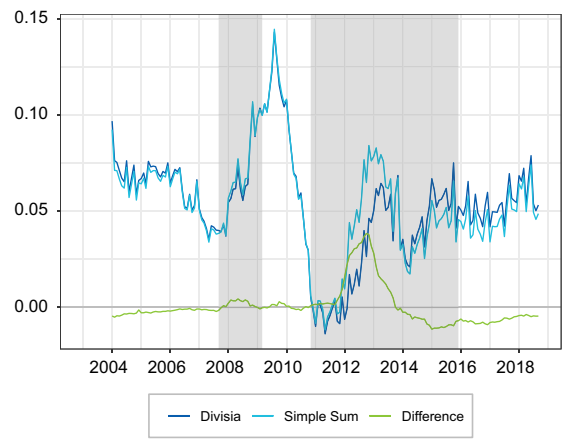

(k) The Netherlands

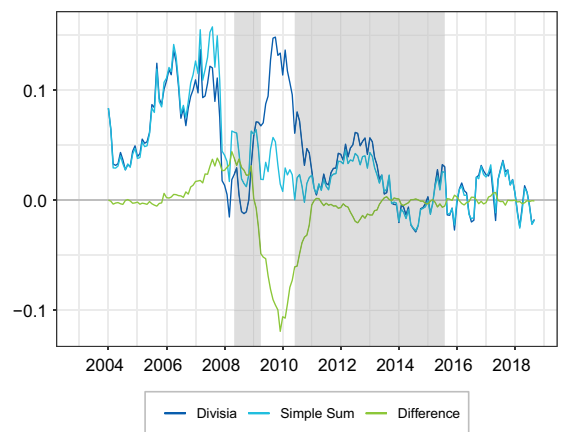

(h) Ireland

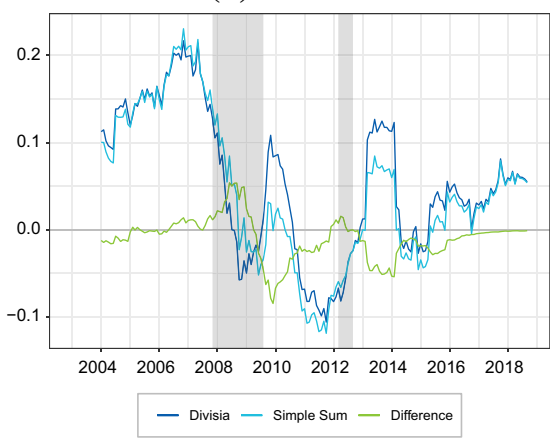

(j) Luxembourg

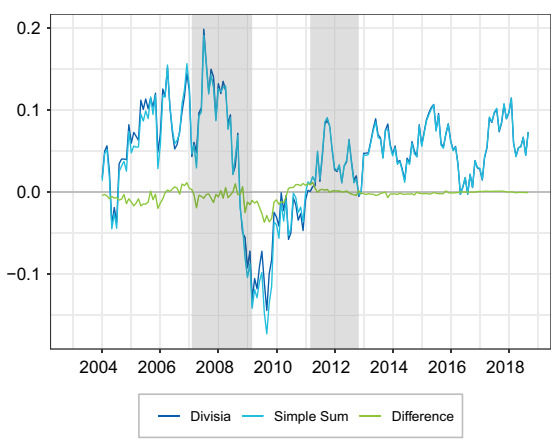

(l) Portugal

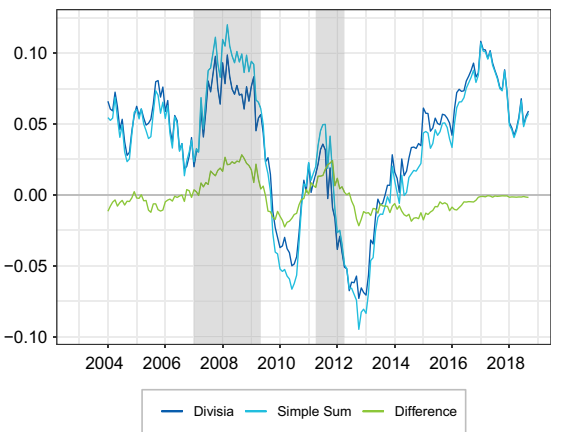

Fig. 12 (continued) 


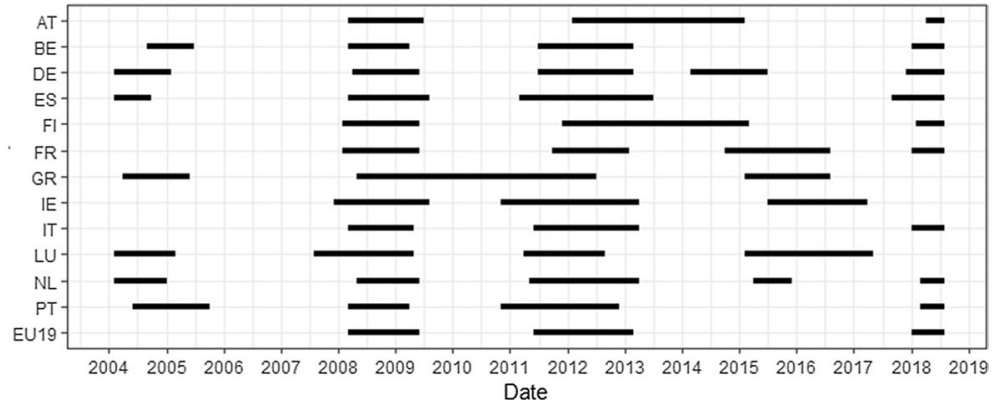

Fig. 13 Recessions in the EA-12 countries according to OECD leading indicators

\section{Appendix 3: Alternative recession indicator}

This appendix shows our results using the OECD leading indicators for defining recessions in euro area countries, see OECD (2019). Although the timing of recessions partly depends on the recession indicator employed (Fig. 13), our main result concerning the predictive content of Divisia aggregates for recessions is clearly confirmed (see Table 6).

Table 6 Predicting recessions in the euro area: results based on OECD leading indicators

\begin{tabular}{|c|c|c|c|c|c|}
\hline & \multicolumn{5}{|c|}{$\mathrm{h}=$ month ahead } \\
\hline & 3 & 6 & 9 & 12 & 18 \\
\hline \multicolumn{6}{|c|}{$\operatorname{Pr}\left(Y_{i, t}=1\right)=\Phi\left(\beta_{0, h}+\beta_{1, h} S P_{i, t-h}+\beta_{2, h} R_{i, t-h}^{L}\right)$} \\
\hline$t$-stat $\beta_{1}$ & $-5.19 * * *$ & $-7.46^{* * *}$ & $-7.14 * * *$ & $-5.72 * * *$ & $-2.22 * *$ \\
\hline$t$-stat $\beta_{2}$ & $7.65 * * *$ & $8.70 * * *$ & $8.46 * * *$ & $5.97 * * *$ & 1.25 \\
\hline pseudo $R^{2}$ & 0.022 & 0.027 & 0.023 & 0.015 & 0.003 \\
\hline AUROC & 0.5937 & 0.5954 & 0.5830 & 0.5595 & 0.4842 \\
\hline \multicolumn{6}{|c|}{$\operatorname{Pr}\left(Y_{i, t}=1\right)=\Phi\left(\beta_{0, h}+\beta_{2, h} R_{i, t-h}^{L}+\beta_{3, h} D I V_{i, t-h}\right)$} \\
\hline$t$-stat $\beta_{2}$ & $4.14 * * *$ & $3.21 * * *$ & $2.74 * * *$ & 1.52 & -1.30 \\
\hline$t$-stat $\beta_{3}$ & $11.03 * * *$ & $11.74 * * *$ & $10.64 * * *$ & $7.42 * * *$ & 0.63 \\
\hline pseudo $R^{2}$ & 0.051 & 0.060 & 0.050 & 0.029 & 0.001 \\
\hline AUROC & 0.6192 & 0.6312 & 0.6248 & 0.6082 & 0.5060 \\
\hline \multicolumn{6}{|c|}{$\operatorname{Pr}\left(Y_{i, t}=1\right)=\Phi\left(\beta_{0, h}+\beta_{1, h} S P_{i, t-h}+\beta_{2, h} R_{i, t-h}^{L}+\beta_{3, h} D I V_{i, t-h}\right)$} \\
\hline$t$-stat $\beta_{1}$ & 0.40 & -1.14 & -1.25 & -1.14 & $-2.18^{* *}$ \\
\hline$t$-stat $\beta_{2}$ & $2.23 * *$ & $2.95 * * *$ & $2.52 * *$ & $1.98 * *$ & 1.26 \\
\hline$t$-stat $\beta_{3}$ & $9.49 * * *$ & $4.73 * * *$ & $8.38 * * *$ & $6.02 * * *$ & -0.57 \\
\hline Pseudo $R^{2}$ & 0.051 & 0.060 & 0.051 & 0.030 & 0.003 \\
\hline AUROC & 0.6188 & 0.6301 & 0.6196 & 0.5957 & 0.4949 \\
\hline
\end{tabular}

The Table shows measures of fit and t-statistics for pooled panel probit models with and without the divergence between the growth rate of M2 Divisia and its simple sum counterpart. SP denotes the spread between the long- and short-term interest rate, $R^{L}$ is the 10 year government bond rate and $D I V$ is the divergence between the growth rate of two monetary aggregates. t-statistics are based on Newey-West standard errors with a autocorrelation length of $h-1 .{ }^{* * *} / /^{* *} /{ }^{*}$ indicate significance at the 1-/5-/10- percent level. Recessions are defined using the OECD leading indicators, see Fig. 13 


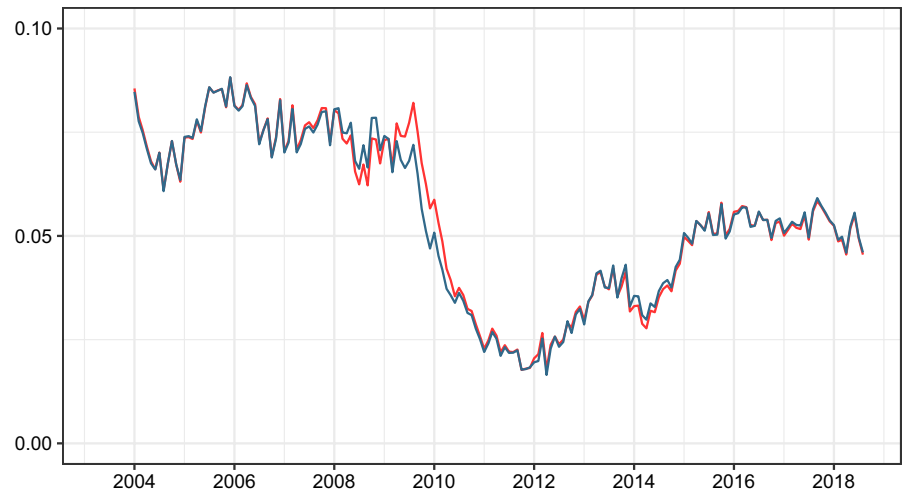

Fig. 14 Divisia aggregates with alternative benchmark rates. Notes Annual growth rates of Divisia aggregates with (1) a constant 100 basis points premium as in Fig. 7 (blue line) and (2) a time-varying premium proxied by the spread between a corporate bond (TRECLYJ) and a government bond (EMESEFIGR) with 10 years maturity (red line). Data source: Thomson Reuters Datastream (color figure online)

\section{Appendix 4: Alternative benchmark rate}

In accordance with Stracca (2004) and Anderson and Jones (2011), the impact of alternative benchmark rates on the Euro area Divisia aggregate is very limited. To illustrate, Fig. 14 shows the annual growth rates of the Euro area Divisia aggregate based on (1) a constant 100 basis points premium as in Fig. 7 (blue line) and (2) a time-varying premium proxied by the spread between a corporate bond and a government bond with 10 years maturity.

\section{References}

Anderson RG, Jones EB (2011) A comprehensive revision of the US monetary services (divisia) indexes. Fed Reserve Bank St. Louis Rev 93(5):325-359

Artis MJ, Kontolemis ZG, Osborn DR (1997) Business cycles for G7 and European countries (Group of 7). J Bus 70(2):249-279

Barnett WA (1978) The user cost of money. Econ Lett 1(2):145-149

Barnett WA (1980) Economic monetary aggregates an application of index number and aggregation theory. J Econom 11:11-48

Barnett WA (2003) Aggregation-theoretic monetary aggregation over the euro area, when countries are heterogeneous. ECB working paper, p 260

Barnett WA (2007) Multilateral aggregation-theoretic monetary aggregation over heterogeneous countries. J Econom 136(2):457-482

Barnett WA, Chauvet M (2011) How better monetary statistics could have signaled the financial crisis. J Econom 161:6-23

Barnett WA, Gaekwad N (2018) The demand for money for EMU: a flexible functional form approach. Open Econ Rev 29(2):353-371

Barnett WA, Su L (2019) Risk adjustment of the credit-card augmented divisia monetary aggregates. Macroecon Dyn 23(supplement):90-114

Barnett WA, Liu J, Mattson R, Noort J (2013) The new CFS divisia monetary aggregates: design, construction, and data sources. Open Econ Rev 24(1):101-124

Belongia MT, Ireland PN (2014) The Barnett critique after three decades: a new Keynesian analysis. J Econom 183(1):5-21 
Belongia MT, Ireland PN (2015) A "working" solution to the question of nominal GDP targeting. Macroecon Dyn 19(3):508

Berge TJ, Jordá O (2011) Evaluating the classification of economic activity into recessions and expansions. Am Econ J Macroecon 3(2):246-277

Billi RM, Söderström U, Walsh C E (2020) The role of money for monetary policy at the lower bound. CEPR Discussion Paper, No, p 14865

Borio CE, Drehmann M, Xia FD (2018) The financial cycle and recession risk. BIS Q Rev, December, pp 59-71

Constâncio V (2018) Past and future of the ECB monetary policy. In: Speech by Vítor Constâncio, vicepresident of the ECB, at the conference on "Central banks in historical perspective: what changed after the financial crisis?", organised by the Central Bank of Malta, Valletta, 4 May (2018)

Darvas Z (2015) Does money matter in the euro area? Evidence from a new divisia index. Econ Lett 133(C):123-126

De Nederlandsche Bank (2018) Combined balance sheet of DNB and Dutch-based MFI, adjusted for breaks (month). https://statistiek.dnb.nl/en/praktisch/datatoelichting/tabellen/statistiek34728 7.aspx

Dery C, Serletis A (2020) Interest rates, money and economic activity. Macroecon Dyn (Forthcoming)

Dias A (2018) Estimating a country's currency circulation within a monetary union. In: Presented at: ninth IFC conference on "Are post-crisis statistical initiatives completed?", 30-31 August. Bank for International Settlements, Basel

El-Shagi M, Kelly L (2019) What can we learn from country-level liquidity in the EMU? J Financial Stab 42:75-83

Estrella A, Mishkin F S (1998) Predicting U.S. recessions: financial variables as leading indicators. Rev Econ Stat 80(1):45-61

European Central Bank (2003) Editorial. Monthly Bulletin, pp 5-8

European Central Bank (2012) Manual on MFI balance sheet statistics

European Central Bank (2017) Manual on MFI interest rate statistics

Fisher P, Hudson S, Pradhan M (1993) Bank of England quarterly bulletin, pp 240-255

Goodhart CAE, Mills TC, Capie F (2019) The slope of the term structure and recessions: evidence from the UK, 1822-2016. CEPR discussion paper (DP 13519)

Hancock M (2005) Divisia money. Bank Engl Q Bull 1:39-46

Jadidzadeh A, Serletis A (2019) The demand for assets and optimal monetary aggregation. J Money Credit Bank 51(4):929-952

Nautz D, Rondorf U (2011) The (in)stability of money demand in the euro area: lessons from a crosscountry analysis. Empirica 38(4):539-553

OECD (2019) Composite leading indicators. https://www.oecd-ilibrary.org/content/data/data-00042-en

Offenbacher EA, Shemesh S (2011) Divisia monetary aggregates for Israel: background note and metadata. https://www.boi.org.il/en/DataAndStatistics/Documents/exp_metadata.pdf

Schunk D (2001) The relative forecasting performance of the divisia and simple sum monetary aggregates. J Money Credit Bank 16:272-283

Stracca L (2004) Does liquidity matter? Properties of a divisia monetary aggregate in the Euro area. Oxf Bull Econ Stat 66(3):309-331

Publisher's Note Springer Nature remains neutral with regard to jurisdictional claims in published maps and institutional affiliations. 